\title{
Sustainable Road Transport: Alternative Fuels, Electrical Vehicles and Environmental Effects
}

\author{
Eda Baspinar \\ Zonguldak Bulent Ecevit University, Department of Environmental Engineering \\ Farabi Campus 67100, Zonguldak, Turkey \\ E-mail: eda.baspinar@yahoo.com \\ Ozgur Zeydan (Corresponding author) \\ Zonguldak Bulent Ecevit University, Department of Environmental Engineering \\ Farabi Campus 67100, Zonguldak, Turkey \\ E-mail: ozgurzeydan@yahoo.com
}

\begin{abstract}
Transportation sector enables the transfer of goods and services that forms the basis of the economy and the work of people. It supports global productivity and is a key for economic growth. On the other hand, transportation is largely based on fossil fuels and generates greenhouse gas emissions. Moreover, it releases other pollutants and creates local air pollution. Although the air pollutant emissions of road transport of Turkey have decreased over the years due to new emission standards, greenhouse gas emisions of the same sector in Turkey have been sharply increased. Therefore, there is an urgent necessity of focusing on sustainable transport strategies to reduce emissions from transportation sector. The sustainability of the road transportation depends on alternative fuels and electric vehicles. Alternative fuels like biodiesel and bioethanol have already been used in motor vehicles for many years. Using alternative fuels reduce the release of air pollutant emissions except nitrogen oxides. However, alternative fuel production generally depends on local farming and not common every part of the world. Electric vehicles are a hope for road transport sustainability. Hybrid electric cars consume less fossil fuel and full electric cars run on only by electricity. If electricity comes from an alternative energy source, transportation by electric vehicles will be much more sustainable since it does not produce any greenhouse gas or air pollutants. This paper briefly discusses motor vehicle air pollution problem and gives some information about Turkish road transport sector emissions. Furthermore, it reviews sustainable road transport options mainly by focusing on alternative fuels and electric vehicles. Also, there exist some suggestions for policy makers about the sustainability of transportation sector.
\end{abstract}

Keywords: Alternative fuels, electrical vehicles, environmental impacts, motor vehicles, sustainable road transport, Turkey

DOI: $10.7176 / \mathrm{JSTR} / 5-3-14$

\section{Sürdürülebilir Karayolu Ulaşımı: Alternatif Yakıtlar, Elektrikli Araçlar ve Çevresel Etkiler}

\begin{abstract}
Özet
Taşımacılık sektörü, malların ve hizmetlerin taşınımını olanaklı kılarak ekonominin ve işgücünün temelini oluşturur. Küresel üretkenliği destekler ve ekonomik gelişim için bir anahtardır. Diğer taraftan, ulaşım ağırlıklı olarak fosil yakıtlara bağımlıdır ve sera gazı emisyonlarına yol açar. Ayrıca, diğer hava kirleticilerinin salınmasıyla yerel hava kirliliğine sebep olur. Türkiye'deki kara yolu ulaşımından kaynaklanan hava kirleticilerinin emisyonları yeni emisyon standartları nedeniyle yıllar içinde azalma gösterirken, aynı sektörün seragazı emisyonları oldukça büyük bir artış göstermiştir. Bu nedenle, ulaşım sektöründen kaynaklı emisyonları azaltmak için sürdürülebilir ulaşım stratejilerine odaklanmaya ciddi bir gereksinim oluşmuştur. Karayolu ulaşımında sürdürülebilirlik alternatif
\end{abstract}

109 | P a g e

www.iiste.org 
yakıtlara ve elektrikli araçlara dayanmaktadır. Biyodizel ve biyoetanol gibi alternatif yakıtlar, motorlu taşıtlarda yıllardan beri kullanılmaktadır. Alternatif yakitların kullanılması azot oksitler haricindeki hava kirleticilerinin salınımında azalmaya sebep olmaktadır. Fakat, alternatif yakıtların üretimi genellikle yerel tarıma bağlı olduğundan dünyanın her yerinde yaygın değildir. Elektrikli araçlar ise karayolu ulaşımının sürdürülebilirliğinde yeni bir umuttur. Hibrit araçlar daha fazla fosil yakıt tüketmekte ve diğer elektrikli araçlar ise çalı̧̧mak için sadece elektriğe ihtiyaç duymaktadır. Elektriğin de alternatif bir enerji kaynağından gelmesi durumunda elektrikli araçlar ile ulaşım, sera gazı emisyonu ve diğer hava kirleticilerini üretmediklerinden çok daha sürdürülebilir olacaklardır. Bu makalede, motorlu araçlar kaynaklı hava kirliliği problemi kısaca tartışılmış ve Türkiye'deki karayolu ulaşım sektöründen kaynaklanan emisyonlar hakkında bilgiler verilmiştir. Sürdürülebilir karayolu ulaşım seçenekleri, alternatif yakıtlara ve elektrikli araçlara odaklanarak yorumlanmıştır. Ayrıca, karar vericiler için karayolu ulaşım sektörünün sürdürülebilirliği hakkında bazı öneriler mevcuttur.

Anahtar kelimeler: Alternatif yakıtlar, çevresel etkiler, elektrikli araçlar, motorlu taşıtlar, sürdürülebilir karayolu ulaşımı, Türkiye

\section{Giriş}

Günümüzde enerji kaynakları, yenilenemeyen (kömür, petrol, doğalgaz ve nükleer enerji) ve yenilenebilir (biyokütle enerjisi, jeotermal enerji, güneş, rüzgâr, hidrojen ve hidro enerji) olarak sinıflandırılmaktadır. Dünya genelinde ısınma ihtiyacı, ulaşım, taşımacılık, endüstriyel faaliyetler ve diğer birçok durumda temel enerji kaynağı olarak fosil yakıtların kullanılması çevre sorunlarını önemli ölçüde artırmıştır. Dünya nüfusunun artmasıyla birlikte enerji talebi de artmaktadır. İnsanoğlu; teknolojik gelişmelerle birlikte daha konforlu yaşam standartlarına ulaşmış olup enerji tüketimi de artmıştır. Küresel çapta ticaretin gelişmesi, insanların kısa veya uzun mesafe seyahat ihtiyacı da ulaşım sektörüne kısa vadede akut çözümler bulunması yönünde, uzun vadede ise çevresel problemlerden dolayı daha çevreci çözümler bulunması yönünde baskı yapmaktadır. Özellikle petrol ve doğalgaz gibi rezerv ömrü sınırlı olan yakıtların azalmasıyla maliyetlerin artmasının sosyal ve ekonomik açıdan ciddi sonuçlar doğurması söz konusudur. Tüm bunlar ulaşım sorununu beraberinde getirmekte ve trafiğe çıkan araç sayısı her geçen gün artmaktadır. Bu durum ise egzoz emisyonlarını artırmış olup çevre kalitesini olumsuz yönde etkilemiş̧ir. Fosil yakıtların kullanılması sonucunda meydana gelen sera gazı emisyonları gibi zararlı emisyonların çevre üzerine olumsuz etkileri bulunmaktadır. İklim bilimciler, atmosferdeki karbondioksit $\left(\mathrm{CO}_{2}\right)$ konsantrasyonlarının, sanayi öncesi döneme (yaklaşık $280 \mathrm{ppm}$ ) kıyasla geçtiğimiz yüzyılda önemli ölçüde arttığını gözlemlemişlerdir. 2019 yılının Ocak ayında $\mathrm{CO}_{2}$ konsantrasyonu 410,83 ppm olarak ölçülmüş olup bu değer 1800'lü yıllara kıyasla yaklaşı \% 47 oranında bir konsantrasyon artışını göstermektedir (McGee, 2019). Metan $\left(\mathrm{CH}_{4}\right)$ ve diazot monoksit $\left(\mathrm{N}_{2} \mathrm{O}\right)$ seviyelerinde de önemli artışlar meydana gelmiştir (Igliński \& Babiak, 2017). Günümüzde, karayolu taşımacıllğ̆ , küresel antropojenik $\mathrm{CO}_{2}$ emisyonlarının önemli bir payından sorumludur (Offer, Howey, Contestabile, Clague, \& Brandon, 2010). Uluslararası Enerji Ajansı'nın (IEA) son verilerine göre 2016 yılının en büyük emisyon kaynağı, toplam küresel $\mathrm{CO}_{2}$ 'nin $\% 42$ 'sinden sorumlu olan ulaştırma sektörüdür (IEA, 2018). Bunun başlıca nedeni petrol kökenli yakıtlara olan bağımlılıktır (Bauer, Hofer, Althaus, Del Duce, \& Simons, 2015).

Fosil yakıt kullanan araçların neden olduğu çevresel etkilerin azaltılması uzun bir süredir dünya gündemindedir. Ulaştırma sektörü kaynaklı çevresel etkiler araç filosunun büyümesiyle daha da artmaktır. Hava kirliliğine ve iklim değişikliğine sebep olan emisyonları azaltmak ve petrol yakıtlarına olan bağımlılıkları en aza indirgemek için mühendisler ve politikacılar, daha az zararlı olan ve sınırlı kaynakları daha az tüketen sürdürülebilir yakıt ve araç alternatiflerini araştırmaktadırlar (Ramachandran \& Stimming, 2015). Sürdürülebilir yakıtlar biyoyakıtlardır (biyodizel ve biyoetanol vb.). Bunlar, birçok ülkede enerjinin kendi kendine yeterliliğini arttırmak, ithalat maliyetlerini azaltmak ve yurt içi tarımsal gelişmeyi güçlendirmek için uzun yıllardan beri kullanılmaktadır. 2000 yılından beri, küresel biyoyakıt tedariki, 2015 yllında dünyadaki ulaşım yakitlarının \%4'ünü oluşturacak oranda artmıştır. Bu önemli artışın, o dönemde biyoyakıtların daha fazla kullanımını teşvik eden, biyoyakıtları petrol yakıtlarına kısmen karıştırmaya yönelik harmanlama kanunlarından ve buna yönelik yürütülen politikalardan kaynaklandığı düşünülmektedir (Araújo, Mahajan, Kerr, \& Silva, 2017). 2015 yılında Brezilya şeker kamışı bazlı, Amerika Birleşik Devletleri mısır bazlı etanolden oluşan küresel biyoyakıt arzının yaklaşı \% 70'ini üretmiş̧ir. Avrupa Birliği; petrol atıkları, yağlar, soya fasülyesi, kolza tohumu ve palmiye yağından üretilen biyodizel kullanmaktadır. Asya'da biyoyakıt kaynağı, uluslararası biyoyakıt ürün pazarının oluşturulmasında şeker kamışı, mısır, buğday ve manyok bazlıdır (Joshi, Pandey, Rana, \& Rawat, 2017). Biyoyakıtlar, hammaddelerine ve üretim teknolojilerine göre dört nesilde sınıflandırılmıştır. Birinci nesil ve en yaygın olarak kullanılan biyoyakıtlar, biyodizel ve biyoetanoldür. İkinci nesil biyoyakttlar için lignoselülozik biyokütle, ana hammadde olarak tanımlanmaktadır. Potansiyel hammaddeler ise otsu ve odunsu bitkiler, tarım ve orman kalıntıları, belediye ve endüstriyel katı atıklardır. Bu teknolojinin ana avantajı, lignoselülozik biyokütlenin tarım arazilerinin kullanılmasını gerektirmemesidir (Liew, Hassim, \& Ng, 2014). Üçüncü ve dördüncü nesil biyoyakıt ise esas olarak

110 | P a g e

www.iiste.org 
alglerden elde edilir. Son zamanlarda yapılan araştırmalar, yüksek lipid içeriğine ve optimum büyüme koşullarına sahip alg türlerinin ideal kombinasyonunun araştırılmasına odaklanmıștır (Dutta, Daverey, \& Lin, 2014).

Karayolu taşımacılığından kaynaklanan $\mathrm{CO}_{2}$ emisyonlarını azaltmaya yönelik diğer alternatif Elektrikli Araçlar (EV)'dir (Figenbaum, 2017). Birçok araştırmacı ulaştırma sektöründe sürdürülebilirliğin elektrikli araçlar ile sağlanacağını belirtmektedir. Merkisz-Guranowska ve diğ. (2013), konvansiyonel araçlardan kaynaklanan olumsuz çevresel etkiyi azaltan ve karayolu taşıma ağının etkin kullanımını garanti eden çevre dostu bir taşıma sistemi tasarlamak için kullanılabilir bir model ortaya koymaktadır (Merkisz-Guranowska, Merkisz, Kozak, \& Jacyna, 2013). Juan Martínez-Lao ve ark.’nın (2017) araştırmasına göre EV’lerin kullanılmasının, ulaştırma sektörünün sürdürülebilirliğini sağlamakta önemli bir yeri vardır. Elektrikli araçların devlet politikaları ile teşvik edilmesi ve yaygınlaşması, otomobil sektörünün sürdürülebilirliğini sağlayan bir alternatiftir (Martínez-Lao, Montoya, Montoya, \& Manzano-Agugliaro, 2017). Almanya $\mathrm{CO}_{2}$ emisyonlarını azaltmaya yönelik çeşitli çalışmalar ve uygulamalar yapan bir ülke olup Almanya Federal Konseyi, 2016 yılında, 2030'dan itibaren fosil yakıtların kullanıldığı İçten Yanmalı Motorlu Taşıtlar (ICEV)’ın yasaklanması kararını onaylamıştır. Almanya, 2050 yılına kadar \%95'lik bir karbon azaltma hedefine sahiptir. Bu da, önemli ölçüde araç elektrifikasyonu gerektirecektir. Bu karara göre, 2030 yılına kadar satılan İçten Yanmalı Motorlu (ICE) otomobiller sadece 2050 yılına kadar kullanılabilir. Çünkü bu tarihten sonra, Almanya'da, ICE ile çalışan herhangi bir otomobilin sirkülasyonuna izin verilmeyecek olup sadece EV'lere izin verilecektir (Heinrichs \& Jochem, 2016). Alman Çevre Örgütü (Deutsche Umwelthilfe) Berlin'de azot dioksite $\left(\mathrm{NO}_{2}\right)$ en çok neden olan dizel araçların yasaklanması için mahkemeye başvurmuştur. Berlin İdare Mahkemesi'nde görüşülen konu ile ilgili 9 Ekim 2018 tarihinde $\mathrm{NO}_{2}$ limitleri hususunda yasal sınırlara mümkün olan en hızlı şekilde uyum sağlanması için dizel araçların yasaklanması gerekliliğinin olduğuna karar verilmiştir. Bu yasağın ilki 1 Haziran 2018 tarihinde Hamburg’ta kısmi olarak uygulanmaya başlamıştı. Bugün Almanya'da Berlin, Stuttgart, Dusseldorf, Aachen ve Frankfurt'ta dizel yasağ1 uygulanmaktadır (Resch, Klinger, Taddei, \& Baker, 2018). Çin Halk Cumhuriyeti, EV kullanımında dünyaya öncülük etmektedir ve yaklaşık 649.000 EV hâlihazırda kullanılmaktadır. Buna ek olarak 2020 yılına kadar bu rakamın 5 milyona ulaşacağına dair iddialı bir plan bulunmaktadır. ABD, yaklaşık $565.000 \mathrm{EV}$ ile dünya çapında ikinci sırada yer almaktadır. Japonya, trafikteki 152.000 EV ile üçüncü sıradadır. Norveç ise trafikteki $135.000 \mathrm{EV}$ ile dördüncü ülke olup Hollanda ise trafikteki 115.000 EV ile beşinci sırada bulunmaktadır. Şu anda, Norveç ve Hollanda tüm ICEV 2025'e kadar trafikten kaldırmayı planlamaktadır. 2016 yılı verilerine göre, 2 milyon EV ve Hibrit Araç (HEV) dünya filosunun yaklaşık \%2'sini oluşturmaktadır (Cecere, Corrocher, \& Guerzoni, 2018). Ancak, bazı temel sorunlar cevapsız kalmaktadır. Örneğin, yeni ve daha büyük EV filolarına güç vermek için yeterli yenilenebilir enerji kaynağı bulunup bulunmayacağı, yeni pillerin üretilmesinde lityum ve kobalt rezervlerinin talebi karşılamaya yeterli olup olmayacağı gibi cevaplanması ve araştırılması gereken konular mevcuttur. Bunun yanı sıra, EV’lerin fosil kökenli yakıtların yanması sonucu elde edilen elektrik enerjisi ile şarj edilmesi halinde sera gazı emisyonlarının azaltılması ile ilgili yapılan çalışmalar anlamını kaybedecektir (Ruiz et al., 2018). Tam Elektrikli Araçların sadece akülerin yardımıyla çalışması nedeniyle akülerin sürekli olarak yeniden şarj edilmesi gerekmektedir. Bunun için gerekli olan elektrik enerjisinin daha fazla sera gazı emisyonuna sebep olan konvansiyonel santrallerden üretilmesi elektrikli araçların kullanım amacına tam anlamıyla ters düşen bir durumdur. Yapılan bir çalışmada, bu sorunun üstesinden gelmek ve EV'lerin batarya bağımlılığını azaltarak menzilini uzatmak için hem yenilenebilir kaynaklara (rüzgâr ve güneş) sahip olan hem de EV'lerdeki aküleri araç seyir halindeyken şarj eden yeni bir şarj etme mekanizması önermiştir (Chellaswamy \& Ramesh, 2017). Bu mekanizma aracın üzerine monte edilen bir rüzgâr kanalı ve güneş panelinden oluşmakta olup daha detaylı bilgiye Chellaswamy ve Ramesh'in çalışmasından ulaşmak mümkündür. Bu araçlar, fosil yakıtlara bağımlılı̆̆ı azaltmak ve böylece sera gazı emisyonunu ve diğer kirleticilerin miktarını azaltmak için kullanılmaktadır.

Çalışmamızda öncelikle, motorlu taşıtların en önemli çevresel etkisi olan hava kirliliği ile sera gazı emisyonlarından bahsedilmiş ve ülkemizdeki motorlu taşıtlar ile bunların emisyonları hakkında bilgiler verilmiştir. Daha sonra, sürdürülebilir ulaşım teknolojilerinden alternatif yakıtlı araçlar, elektrikli araçlar ve bunların çevresel etkileri üzerinde durulmuştur. Çalışmada motorlu kara taşıtları içerisinde oldukça büyük bir yere sahip olan otomobiller üzerinde daha ağırlıklı olarak durulmuştur. Son olarak da elde edilen bulgular 1şığında karayolu ulaşımının daha sürdürülebilir hale gelmesi için öneriler sunulmuştur.

\section{Motorlu Taşıtlar ve Hava Kirliliği}

Bazı araştırmacılar, ulaşım hizmetlerinin büyük ekonomik ve sosyal faydalarından daha çok olumsuz çevresel etkilere neden olduğunu belirtmektedir (Van Lier \& Macharis, 2014). Motorlu taşıtlardan salınan kirleticiler ortamda bulunma konsantrasyonuna göre sağlı̆̆1 etkileme potansiyeline sahiptir. Bu kirleticiler ya kaynaktan doğrudan salınmakta ya da atmosferik reaksiyonlar sonucunda oluşmaktadır (Romieu, 1997). Motorlu taşıtlardan kaynaklanan hava kirleticileri; egzoz, yakıt deposu ve karbüratörden gelmektedir. Egzoz emisyonları motordaki yakıtın yanmasından kaynaklanmaktadır. Araç hareket ederken, çalışır konumdayken (rölanti) veya yakıt ikmali yaparken buharlaşan emisyonlar atmosfere salınmaktadır. Motorlu taşıtlardan kaynaklanan emisyonlar; yakıt türü,

111 | P a g e

www.iiste.org 
aracın yaşı/bakım durumu, yol özellikleri, sürücünün kullanım şekli gibi birçok faktöre bağlı olarak farklılıklar göstermektedir (Flachsbart, 1997). Tablo 1'de motorlu taşıtlardaki emisyon kaynakları ve atmosfere salınan kirleticiler gösterilmektedir (EEA, 2018).

Tablo 1. Motorlu taşıtlarda emisyon kaynakları ve hava kirleticileri

\begin{tabular}{|l|l|}
\hline Emisyon Kaynağı & Kirleticiler \\
\hline Egzoz emisyonu & $\mathrm{CO}_{2}, \mathrm{CO}, \mathrm{UOB}, \mathrm{NOx}, \mathrm{PM}$ \\
\hline Buharlaşma kayıpları & $\mathrm{UOB}$ \\
\hline $\begin{array}{l}\text { Tekerleklerden kaynaklanan (frenleme ve yoldan toz kalkması vb.) } \\
\text { emisyonlar }\end{array}$ & $\mathrm{PM}$ \\
\hline
\end{tabular}

Sağlıkla ilgili başlıca kirleticiler arasında karbon monoksit (CO), azot oksitler (NOx), partikül maddeler (PM) ve uçucu organik bileşikler (OUB)'dir. Kurşun ise daha önceleri motor performansını iyileştirmek için yakıta eklenen bir kirletici idi (Flachsbart, 1997). Günümüzde kullanılan kurşunsuz benzindeki oktan seviyesini arttırmak ve CO emisyonlarını azaltmak için katkı maddesi olarak metil tersiyer bütil eter kullanılmaktadır (Agency for Toxic Substances and Disease Registry (ATSDR), 1996). Yer seviyesindeki Ozon $\left(\mathrm{O}_{3}\right)$ ise atmosferdeki uçucu organik bileşiklerin ve azot oksitlerin güneş ışığı etkisiyle gerçekleşen reaksiyonları sonucunda oluşan ikincil hava kirleticisidir (Atkinson, 2000).

\section{Türkiye'de Karayolu Ulaşımı ve Kirletici Emisyonları}

Ülkemizdeki motorlu kara taşıtlarının sayısı son yıllarda hızlı bir artış göstermiş̧ir. Türkiye İstatistik Kurumu Ulaştırma ve Haberleşme İstatistiklerine göre Türkiye'deki motorlu kara taşıt sayısı 1966 yılında 231.977 iken 2018 y1lında bu rakam 22.865.921'e ulaşmıştır. 2018 yılsonu itibari ile Türkiye'deki otomobillerin yakıt türleri; benzin, dizel, sıvılaştırılmış petrol gazı (LPG) ve yakıt türü bilinmeyen araçlar olmak üzere dört grupta değerlendirilmektedir. Yakıt türüne göre otomobillerin (hafif binek araçlar) dağılımı Tablo 2'de verilmiştir (TUİK, 2018). Yakıt türüne göre otomobillerin \%24,9'unu (3.089.626 adet) benzinli araçlar oluştururken \%36,8'i (4.568.665 adet) dizel yakıt ve \%37,9'u (4.695.717 adet) da LPG kullanmaktadır. Otomobillerin \%0,4'ü ise ruhsat işlemlerinde yakıt türü boş bırakılan veya sehven hatalı veri girişi yapılan taşıtlar ile elektrikli taşıtlardan oluşmaktadır.

Tablo 2. Yakıt Türüne Göre Otomobillerin Sayısı
\begin{tabular}{|l|r|c|}
\hline Yakıt Türü & Sayısı (adet) & Yüzde (\%) \\
\hline Benzin & 3.089 .626 & 24,9 \\
\hline Dizel & 4.568 .665 & 36,8 \\
\hline LPG & 4.695 .717 & 37,9 \\
\hline Diğer & 44.182 & 0,4 \\
\hline Toplam & $\mathbf{1 2 . 3 9 8 . 1 9 0}$ & $\mathbf{1 0 0}$ \\
\hline
\end{tabular}

Ülkemizde araç sayısının yıllara göre artmasına rağmen emisyon miktarlarında belirgin bir azalma söz konusudur. Bunun sebebi olarak da araç filosunun yenilenmesi ve düşük emisyonlu (Euro 3, 4 ve 5 gibi) araçların sayısının artması olduğu düşünülmektedir. Türkiye'de karayolu ulaşımından kaynaklanan $\mathrm{NO}_{\mathrm{x}}, \mathrm{PM}_{10}, \mathrm{PM}_{2.5}$, CO ve Metan dışı uçucu organik bileşiklerin (NMVOC) son 10 yıllık emisyon değerleri Tablo 3'de verilmiştir (OECD, 2018).

Tablo 3. Türkiye'de Karayolu Ulaşımından Kaynaklanan Emisyonlar (kiloton)

\begin{tabular}{|l|r|r|r|r|r|r|r|r|r|r|}
\hline Kirletici & $\mathbf{2 0 0 7}$ & $\mathbf{2 0 0 8}$ & $\mathbf{2 0 0 9}$ & $\mathbf{2 0 1 0}$ & $\mathbf{2 0 1 1}$ & $\mathbf{2 0 1 2}$ & $\mathbf{2 0 1 3}$ & $\mathbf{2 0 1 4}$ & $\mathbf{2 0 1 5}$ & $\mathbf{2 0 1 6}$ \\
\hline NOx & 154,42 & 145,73 & 134,34 & 124,36 & 117,40 & 113,76 & 132,06 & 119,77 & 116,28 & 109,70 \\
\hline PM $_{10}$ & 10,99 & 10,16 & 9,83 & 9,00 & 8,61 & 8,14 & 10,09 & 9,07 & 8,46 & 7,89 \\
\hline PM $_{2.5}$ & 11,14 & 10,96 & 10,79 & 10,49 & 10,20 & 9,90 & 9,61 & 9,31 & 9,02 & 8,72 \\
\hline CO & 358,28 & 326,74 & 401,96 & 352,24 & 330,03 & 301,16 & 281,82 & 265,74 & 244,90 & 235,83 \\
\hline NMVOC & 62,83 & 58,95 & 58,84 & 54,85 & 52,48 & 49,94 & 48,31 & 46,49 & 44,65 & 44,26 \\
\hline
\end{tabular}

Türkiye'de toplam sera gazı emisyonun yıllar geçtikçe artış gösterdiği bilinmektedir. 2015 yılında Türkiye'nin toplam sera gazı emisyonu 475,1 milyon ton $\mathrm{CO}_{2}$ eşdeğerine yükselmiştir. Bu değerin \%16's1 (75.789 kiloton $\mathrm{CO}_{2}$-eşd.) ulaştırmadan kaynaklanmaktadır. Türkiye'deki karayolu ulaşımı ise tek başına bu değerin \%91,4'ünden (69.309 kiloton $\mathrm{CO}_{2}$-eşd.) sorumludur. Tablo 4'de Türkiye'nin karayolu ulaşımından kaynaklanan sera gazı emisyon miktarları gösterilmiştir (ÇŞB, 2018). 
Tablo 4. Karayolu Ulaşımından Kaynaklanan Sera Gazı Emisyonları (kiloton $\mathrm{CO}_{2}$ eşdeğeri)

\begin{tabular}{|r|r|r|r|r|r|r|r|r|r|r|}
\hline & $\mathbf{1 9 9 0}$ & $\mathbf{1 9 9 5}$ & $\mathbf{2 0 0 0}$ & $\mathbf{2 0 0 5}$ & $\mathbf{2 0 1 0}$ & $\mathbf{2 0 1 1}$ & $\mathbf{2 0 1 2}$ & $\mathbf{2 0 1 3}$ & $\mathbf{2 0 1 4}$ & $\mathbf{2 0 1 5}$ \\
\hline Karayolu & 24.777 & 29.760 & 31.850 & 35.532 & 39.941 & 40.899 & 56.310 & 62.889 & 66.967 & 69.309 \\
\hline
\end{tabular}

\section{Sürdürülebilir Ulaşım Teknolojileri}

Ulaşım sektörü petrolün tüketilmesinde büyük bir paya sahip olup dünya enerjisinin en hızlı büyüyen tüketicisidir (Amjad, Neelakrishnan, \& Rudramoorthy, 2010). 2014 yılında, diğer enerji türlerine kıyasla, petrolün, taşıma sektöründe kullanımı \%94 oranındadır. 2035 yılına kadar, bu oranın \%89'a düşmesi beklenmektedir (BP, 2018; Türkiye Petrolleri, 2016; Van Vliet, Brouwer, Kuramochi, Van Den Broek, \& Faaij, 2011). Karayolu sektöründeki petrol ürünleri tüketiminin ulaşım sektörüne oranı yaklaşı $\% 70$ olup, bu durum karayolu sektörünün tüm ulaşım sektörünün enerji tüketiminde hayati bir rol oynadığını göstermektedir (B. Lin \& Xie, 2013). Petrol fiyatlarındaki değişkenlik ve emisyonlar, ulaştırma sektörünü sürdürülemez bir rotaya oturtmuştur (Martínez-Lao et al., 2017). Ulaştırma, ekonominin tüm kilit taşları olan malların ve hizmetlerin transferini ve insanların işlerini yapmasını sağlayarak, küresel üretkenliği destekleyen, sonuç olarak ekonomik büyüme için anahtar bir yoldur. Bu nedenle ulaşım ihtiyacını, ulaşımdan kaynaklanan $\mathrm{CO}_{2}$ emisyonlarını azaltma ihtiyacıyla bağdaştırmak önemlidir (Heidrich et al., 2017). İklim değişikliği ile mücadele ve fosil kaynakların potansiyel azlığı nedeniyle ulaştırma sektöründe sürdürülebilir çözümlere ihtiyaç duyulmaktadır. Bu hedefe ulaşmanın ümit verici bir yolu, bir yandan enerjinin daha rasyonel bir şekilde kullanılmasını ve diğer yandan da yenilenebilir enerji kaynaklarının uygulanmasını gerektiren sürdürülebilir enerjinin istihdam edilmesidir (Peura, 2013). Bu açıdan esnek yakıtlı araçlar (FFV) veya biyoyakıtlı araçlar, bataryalı elektrikli araçlar (BEV), fişli (plug-in) hibrit elektrikli araçlar, hibrit araçlar (HEV) gibi yenilikçi teknolojilerin kullanılmasıyla fosil yakıtlara olan bağımlılı̆̆ın azaltılmasının, ulaştırma sektörünün daha sürdürülebilir olmasına yönelik umut verici bir adım olduğu görülmektedir (Nanaki \& Koroneos, 2013). Enerji verimliliğinin artırılması, toplam enerji tüketimini azaltabilir ve EV'leri (elektrikli araçlar) kullanmak, emisyonları yerel olarak azaltabilir (Li, Chen, \& Wang, 2017).

\subsection{Biyodizel}

Yenilenebilir ve çoğunlukla yerli kaynaklardan üretilen biyodizel, sürdürülebilir bir enerji kaynağıdır ve bu nedenle ulaşım için enerji gereksinimlerinin sağlanmasında bölgesel olarak daha önemli bir rol oynamaktadır. Bu nedenle, 2000'li yılların başında birçok araştırma biyodizel motor performanslarına ve emisyonlarına odaklanmıştır (Xue, Grift, \& Hansen, 2011).

Birçok ülke biyodizel karışımlı yakıtları, fosil yakıt kullanımının ulaşım amacıyla büyümesini yavaşlatmak için kullanmaktadır. Türkiye'de ise 16.06.2017 tarihli 30098 numaralı Resmi Gazete'de yayımlanan ve 01.01.2018 tarihinde yürürlüğe giren Motorin Türlerine Biodizel Harmanlanması Hakkında Tebliğ'in 5. Maddesi'nde "Dağıtıcı lisansı sahipleri tarafından, bir takvim yılı içerisinde, ithal edilen ve kara tankeri dolum üniteleri hariç rafinericiden temin edilen motorininin toplamına, en az $\% 0,5(\mathrm{~V} / \mathrm{V})$ oranında yerli tarım ürünlerinden ve/veya bitkisel atık yağlardan üretilmiş biodizelin harmanlanmış olması zorunludur.” ibaresi yer almaktadır.

Biyodizel (yağ asidi metil esterleri, FAME) genellikle bir bitkisel yağın metanol ve bir potasyum hidroksit katalizörü ile reaksiyona girdiği transesterifikasyon olarak bilinen kimyasal bir işlemle bitkisel yağlardan ve hayvansal yağlardan türetilir (Kousoulidou, Fontaras, Mellios, \& Ntziachristos, 2008). Ek olarak biyodizel, serbest yağlı asitlerin düşük molekül ağırlıklı alkollerle esterleştirilmesiyle üretilebilir. Hammadde, yağ tohumu ekinlerinden, kızartma yağından veya hayvansal yağlardan elde edilenler olabileceği gibi bitkisel yağ da hammadde olabilir. Soya çoğunlukla ABD'de, kolza ve ayçiçeği de Avrupa'da kullanılmaktadır. Diğer hammaddeler arasında hindistan cevizi ve hurma yağı da bulunmaktadır. Biyodizelin hammaddesi bölgeye göre değişebileceğinden, farklı kaynakların çeşitli yağlı asit profillerinin biyodizel yakıtın özelliklerini nasıl etkileyebileceğini bilmek önemlidir (Knothe \& Steidley, 2005).

Bir yağlı ester molekülünün fiziksel ve yakıt özelliklerini etkileyen yapısal özellikler genel olarak; zincir uzunluğu, doymamışlık derecesi ve zincirin dallanmasıdır. Yağ asidi profilinden etkilenen biyodizelin önemli yakıt özellikleri ve çeşitli yağlı esterlerin yapısal özellikleri, yanma ve egzoz emisyonları ile ilişsili setan sayısı, yanma 1sısı, soğuk akış, oksidatif kararlılık, viskozite ve kayganlıktır. Bu nedenle, tüm yakıtın özelliklerini iyileştirmek için belirli yağ esterlerini yakıtta istenen özellikler ile zenginleştirmeye çalışmak makul görünmektedir (Kousoulidou et al., 2008).

Dizel ve biyodizel arasındaki en önemli bileşim farkı oksijen içeriğidir. Biyodizel, enerji yoğunluğunu azaltan \%10-12 oksijen içerir (Graboski \& Mccormick, 1998). Genel olarak, oksijen içeriği dişında biyodizel, petrol kökenli dizelden farklı olarak şu özelliklere sahiptir: Kükürt, aromatik içeriği, çok halkalı aromatik hidrokarbonlar ve toksisite yoktur. Daha yüksek setan değerine ve düşük 1sıtma değerine sahiptir. Daha iyi yağlama, daha yüksek viskozite, yüksek parlama noktası ve biyobozunabilirlik özelliği vardır (Kousoulidou et al., 2008).

Dizelde ise oksijen seviyesi \%0,6'dan daha düşüktür. Literatürdeki çoğu çalışmada biyodizelin yüksek oksijen

113 | P a g e

www.iiste.org 
içeriği nedeniyle NOx seviyelerinin arttığı bildirilmiştir (Chattopadhyay \& Sen, 2013; Ganapathy, Gakkhar, \& Murugesan, 2011; Lahane \& Subramanian, 2015). Birkaç araştırmacı, biyodizel yakıtla bağlanmış oksijenin NOx emisyonlarını arttırdığı fikrini reddeden bir sonuca ulaşmışlardır (Lapuerta, Armas, Ballesteros, \& Fernández, 2005; Ng, Ng, \& Gan, 2012; Zhu et al., 2013). An ve diğ.'nin gözlemleri; B100 kullanımında daha düşük silindir içi basınç ve ısı tahliye oranı ile NOx konsantrasyonunda düşüş olduğunu göstermiştir (An et al., 2013).

Biyodizel yakıttaki yüksek oksijen içeriği nedeniyle kirletici madde içindeki NOx emisyonu artmaktadır. Yakıt özelliklerinin yanı sıra, hız ve yük gibi motor parametreleri de NOx emisyonlarını etkilemektedir. Shirneshan ve diğ., NOx konsantrasyonunun motor yükündeki artışla arttığını göstermiştir. Biyodizel karışımlı yakıt, test edilen tüm motor yüklerinde dizelden daha yüksek NOx göstermiştir ve bu eğilim daha fazla yüklerde daha belirgin olmuştur (Shirneshan, Almassi, Ghobadian, Borghei, \& Najafi, 2012). Raheman ve diğ., NOx konsantrasyonlarının motor yükündeki artışla arttığını belirtmişlerdir. Motor devirleri ayrıca NOx'i etkilemede hayati bir rol oynar (Raheman \& Kumari, 2014). Düşük devirde, yanma gazlarının kalma süresinin arttığı ve daha yüksek NOx emisyonu oluştuğu tespit edilmiştir. Bu normalde tam yükte ve düşük motor devrinde olmaktadır. Bu nedenle, NOx emisyonlarının motor devriyle ters orantılı olduğu söylenebilir (Ban-Weiss, Chen, Buchholz, \& Dibble, 2007). Biyodizel kullanımının NOx emisyonlarına etkisi incelendiğinde umut verici bir tablo ile karşılaşmak maalesef mümkün görünmemektedir. Saf biyodizel kullanımı, hem binek otomobillerden hem de ağır yük araçlarından kaynaklanan NOx emisyonlarının artmasına yol açmaktadır (Kousoulidou et al., 2008).

NOx emisyonlarının aksine, biyodizel kullanımı ile PM, hidrokarbon (HC) ve CO emisyonlarında önemli oranda azalma sağlanabilmektedir (Xue et al., 2011). Yakıttaki biyodizel oranlarına göre NOx, PM, CO ve HC emisyonlarının değişimi Şekil 1'de gösterilmektedir (Meshram, Thote, Singh, \& Pakhare, 2013). EPA 2002'de, çeşitli biyodizel karışımlarının emisyonlarını geleneksel dizel ile karşılaştıran bir rapor hazırlamıştır. B100 (\%100 biyodizel) için $\% 67$ daha az hidrokarbon, $\% 48$ daha az karbon monoksit, $\% 47$ daha az partikül madde, $\% 80$ daha az poliaromatik hidrokarbon ve \%10 daha fazla NOx ürettiğini bulmuşlardır (Meshram et al., 2013).

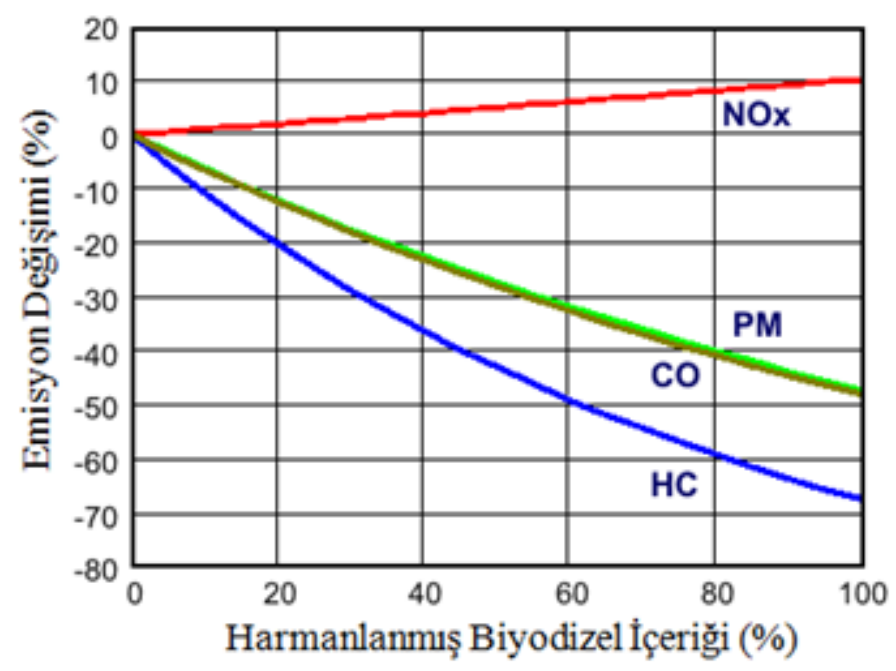

Şekil 1. Biyodizel karışımlarının egzoz emisyonlarına etkisi (Meshram et al., 2013).

\subsection{Biyoetanol}

Biyodizel gibi biyoetanol de sıvı biyoyakıttır. Nişasta bitkilerinden (mısır, buğday ve manyok), şeker bitkilerinden (pancar ve kamış) ve selüloz bitkilerinden yapılmaktadır. Biyoetanol üretiminde ilk olarak bir hammadde mahsulünü mayalanabilir şekerler haline dönüştürmek için enzim amilazları kullanılmaktadır. Daha sonra mayaya şekerleri alkol ve karbon dioksite fermente etmek için maya eklenmekte ve sıvı fraksiyon etanol üretmek üzere damıtılmaktadır. Biyoetanol için hammaddelerin mevcudiyeti mevsime ve coğrafi bölgelere göre değişebilmektedir. Bu nedenle biyoetanol üretmek için kullanılan ürün seçimi, geçerli toprak ve iklim koşullarına bağlıdır. Örneğin Brezilya'da şeker kamışı çok yüksek şeker içeriği ve yakıt verimi nedeniyle tercih edilen besleme malzemesidir. Kuzey Amerika'da, 50’den fazla üretim tesisi mısır gibi nişasta ürünlerinden yakıt etanolü üretmektedir. Çoğu Avrupa ülkesinde etanol şeker pancarı ve tahıl kullanılarak üretilmektedir. Bununla birlikte hammadde fiyatlarının da oldukça değişken olduğu ve bunun biyoetanolün üretim maliyetlerini etkileyebileceği unutulmamalıdır (Kousoulidou et al., 2008).

Biyoetanol farklı şekilde yakıt olarak kullanılabilir: benzinle bir karışım olarak (\%5-85 arasında)

114 | P a g e

www.iiste.org 
kullanılabilmektedir. Tüm benzinli motorlarda \%5'lik bir karışım olarak kullanılmaktadır, düşük bir orandaki alkol-benzin karışımı (E10 'gasohol' olarak da bilinen \%10'luk etanoldur) etanol doğrudan veya motorda çok az modifikasyon yapılarak kullanılabilmektedir. Bununla birlikte, yüksek E85 karışımları araçta birkaç değişiklik gerektirmektedir. Motorları uygun şekilde modifiye edilmiş araçlarda benzin yerine kullanılabilmektedir (Kousoulidou et al., 2008).

Esnek Yakıtlı Araçlar (FFV'ler) Brezilya'da 2003 yılında piyasaya sürülmüştür ve piyasaya sürüldüklerinden bu yana ticari başarı elde etmişlerdir. Sonraki yıllarda, ortalama etanol fiyatlarının benzine kıyasla çok daha az olduğundan konu önem kazanmıştır (De Souza et al., 2018). FFV'ler bugün Brezilya filosunda satılan yeni araçların \%90’ından fazlasını temsil etmektedir ve tüketici talebi nedeniyle bu araçlar ülkenin tüm hafif araç filosunun yaklaşık yarısını oluşturmaktadır (Sozinho, Gallardo, Duarte, Ramos, \& Ruiz, 2018). Günümüzde, benzin-etanol karışımının artışı \%25 - 27 arasındadır ve tüketiciler, FFV'lerini doldurmak için \%100 etanol (E100) kullanabilmektedir (De Souza et al., 2018). Dizel motorlarda dizel yakıt karışımı olarak da bilinen "E-dizel” yakıt karışımları olarak kullanılabilmektedir. Dizel motorlarda biyodizel ile harman olarak ("BE-dizel” yakıt karışımı olarak da bilinir) kullanılabilmektedir. Etanolün araç yakıtı olarak uygunluğu, yüksek performanslı bir yarış motorunda yakıt olarak kullanılmasıyla kanıtlanmıştır (Le Mans’ta kullanılmıştır) (Kousoulidou et al., 2008).

Genel olarak, çoğu çalışma etanol-benzin, etanol-dizel ve etanol-biyodizel karışımları için PM emisyonları ile ilgili düşüşleri göstermektedir. Buji ateşlemeli motorlar üzerindeki etkisi oldukça değişken olmakla birlikte, PM emisyonları dizel motorlara kıyasla çok daha azdır. E10 etanol-dizel karışımları ile ilgili olarak; motor tipi, sürüş koşulları, setan sayısı gibi özellikler ne olursa olsun binek otomobillere ilişkin PM emisyonlarının ortalama azalması \%5'ten \%67'ye kadar değişmektedir (Kousoulidou et al., 2008). Bununla birlikte, ağır vasıtalarda E10 etanol-dizel karışımlarının kullanılmasının \%23 - \%44 mertebesinde daha önemli azalmalar ile sonuçlanması umut vericidir. Buna ek olarak, setan sayısının değişken olduğu durumlarda, dizel yakıtı ile uyumlu olan setan sayısını arttırarak E10 karışımları ile beslenen binek otomobillerde yapılan deneylerde PM emisyonlarının \%25 - \%29 oranında azaldığı görülmüştür (Kousoulidou et al., 2008).

E10'a kadar olan etanol-benzin karışımından elde edilen ana sonuç, $\mathrm{NO}_{\mathrm{x}}$ emisyonları ile ilgili önemli bir değişikliğin görülmemesidir. Bazı çalışmalar E10 karışımlarının genellikle benzin ile kıyaslandığında daha yüksek NOx emisyonuna neden olduğunu göstermektedir (Hsieh, Chen, Wu, \& Lin, 2002). Bazı çalışmalarda emisyonların kısmen azaldığ 1 , bazılarında da kısmen arttığı ve bazılarında ise belirgin bir şekilde azaldığ belirtilmiştir. (He, Wang, Hao, Yan, \& Xiao, 2003; Knapp, Stump, \& Tejada, 1998). Örneğin E20 etanol-benzin karışımları ile ilgili olarak, \%-17 ile \%+79 arasında değişen NOx emisyonları elde edilmiştir (Kousoulidou et al., 2008). Buna karşın DeServes (2005), E85 karışımlarına kadar farklı sürüş çevrimlerinde üç Euro 4 aracı test etmiş olup E85 karışımı kullanıldığında tüm araçlarda önemli ölçüde NOx azalması (\%-70’e kadar) tespit etmiştir. Bu durum yeni teknoloji araçları ve İsveç’te yaygın olarak kullanılan bir karışımla ilgili olduğundan bu bulgunun evrensel bir karaktere sahip olup olmadığını araştırmak için ek testlerle tekrarlanması gerektiği bildirilmiştir.

Çalışmaların çoğunda Etanol-dizel karışımlarının NOx emisyonlarının artmasına yol açtığı bildirilmiştir. Bununla birlikte çalışmanın E10 sonuçları \%-49 seviyesindeki önemli bir düşüş ile \%51 seviyesinde önemli bir artış aralığını belirtmektedir (Kousoulidou et al., 2008).

\subsection{Ikinci Jenerasyon Biyoyakitlar}

İkinci nesil biyoyakıtlar biyokütle-sıvı teknolojilerinden türetilmiştir. Tipik örnekler Bio-DME (Biyo-DimetilEter), biyometanol, karışık alkoller (çoğunlukla etanol, propanol ve bütanol karışımı, bazı pentanol, hekzanol, heptanol ve oktanol) ve Fischer-Tropsch dizel veya BTL'dir (Biyokütleden sivilara). Bütün bu yakıtlar biyokütlenin gazlaştırılmasıyla üretilen sentez gazından türetilebilmektedir. Bununla birlikte enerji santrallerinde ve gaz-sıvı süreçlerinde çok büyük ölçeklerde yapılan kömür veya doğalgazdan daha kolay üretilebilmektedir. Bu nedenle, benzer yakıtlar hem biyo hem de biyo olmayan besleme stoklarından üretilebilmektedir. Fischer-Tropsch biyodizelinin, çok düşük aromatik içerik ve eser kükürt içeren çok yüksek kalitede olması beklenmektedir. Buna ek olarak, ikinci nesil biyoyakıtlar, ilk nesil biyoyakıtlara kıyasla daha az oksijen içerir ve bu nedenle ikinci nesil biyoyakıtlardan gelen egzoz emisyonları, birinci nesil biyodizele kıyasla daha düşüktür. Ayrıca, biyoetanolden türetilen ikinci nesil biyoyakıtların, kimyasal bileşimde farklılık göstermemeleri nedeniyle birinci nesil biyoetanole kıyasla, egzoz emisyonları ile ilgili sapmaları göstermeleri beklenmemektedir (Kousoulidou et al., 2008). 


\subsection{Elektrikli Araçlar}

Ulaştırma sektöründe sürdürülebilirlik üzerine birçok araştırmacı aynı noktada buluşmaktadır: Elektrikli araçlar. Martínez-Lao ve ark.'nın (2017) araştırmasına göre EV'lerin kullanılmasının, ulaştırma sektörünün sürdürülebilirliğini sağlamakta önemli bir yeri vardır. Elektrikli araçların teşvik edilmesi ve yaygınlaşması, otomobil sektörünün sürdürülebilirliğini sağlayan bir alternatiftir (Martínez-Lao et al., 2017). Elektrikli araçlar, birincil güç kaynağı olarak elektrik motoru kullanan araçlardır. EV'ler şarj edilebilir pillerde depolanan elektrik enerjisini kullanırlar. Literatürde EV'ler çok farklı şekillerde sınıflandırılmıştır. Ancak bizim çalışmamızda üretim aşamasına geçen, geliştirilen ve piyasada en çok kullanılan EV tipleri göz önüne alınarak yapılan sınıflandırma Şekil 2'de gösterilmiştir (Rind, Ren, Hu, Wang, \& Jiang, 2017). EV'lerin en temel özelliği egzoz emisyonlarının olmaması veya düşük olmasıdır. EV'ler, sınırlı enerji depolama kapasitesi nedeniyle motorlu araçlara kıyasla nispeten daha kısa sürüş mesafelerine sahiptir. İçten yanmalı motorlu araçlar (ICEV) ve elektrikli araçların kısa bir karşılaştırması Tablo 5'de gösterilmektedir (Vidyanandan, 2018). Elektrikli araçlar özellikle sessiz sürüş ve düşük emisyon gibi özellikleriyle ICEV’lere göre daha çok öne çıkmaktadır. Özellikle, elektriğin yenilenebilir kaynaklardan üretilmesi durumunda yaşam döngüsü analizlerinde sera gazı emisyonları ve hava kalitesine olan etkiler çok daha düşük çıkmaktadır. Bu nedenle de doğal kaynakların daha az tüketilmesi ve iklim değişikliği ile mücadele için EV'ler en çok üzerinde durulması gereken alternatif ulaşım türlerinden biridir (Vidyanandan, 2018).

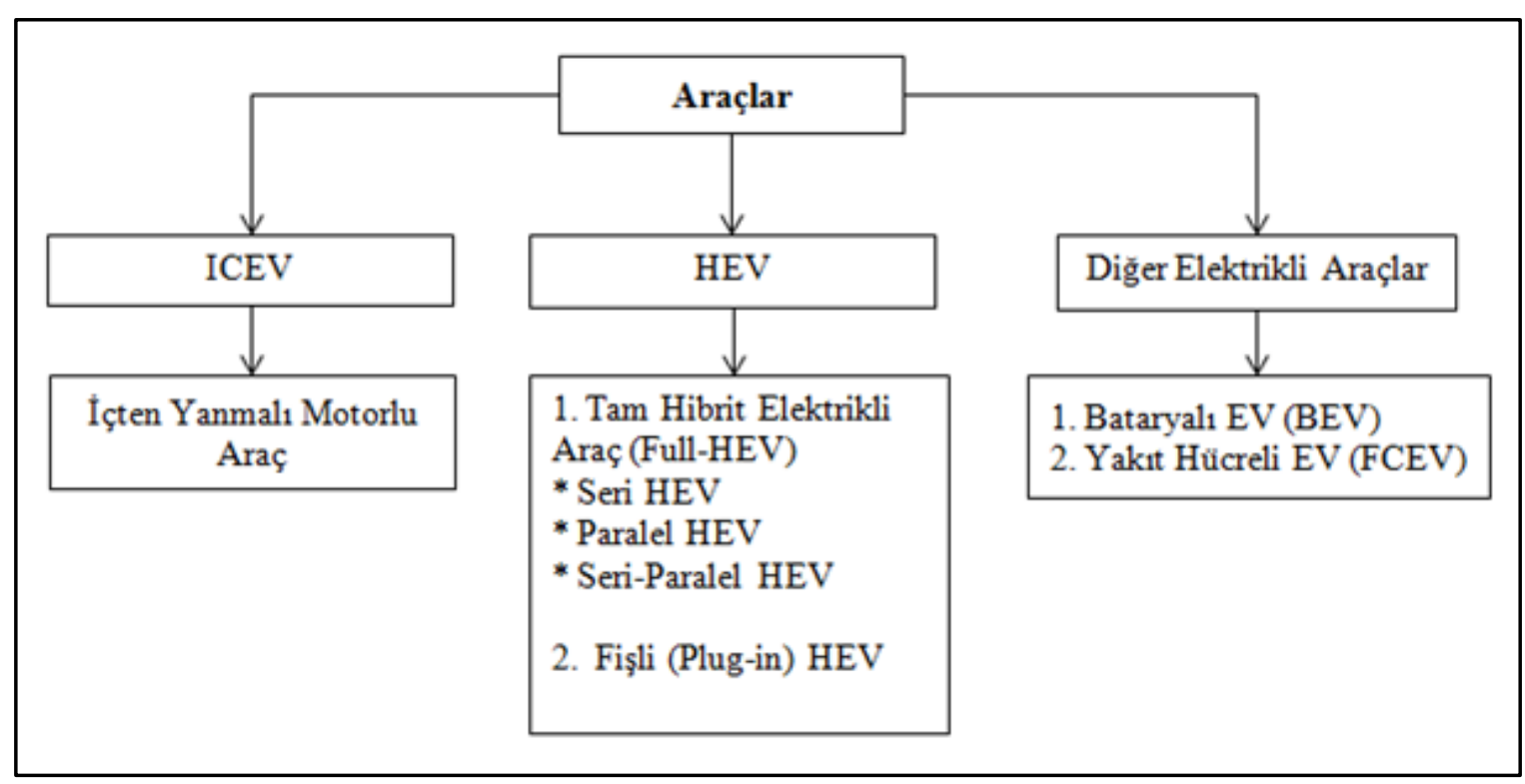

Şekil 2. Araçların Sınıflandırılması

EV'lerin şarj edilmesi için kullanılan elektrik enerjisinin yenilenebilir kaynaklardan sağlanması gerektiği araştırmacıların neredeyse tamamı tarafindan kabul edilmektedir. Xiaomin $\mathrm{Li}$ ve diğ., yenilenebilir enerjilerdeki \%1 artışın, EV taleplerinde yaklaşık \%2-6 oranında artış sağladığını belirtmektedir (Li et al., 2017). EV pilleri yenilenebilir kaynaklardan üretilen elektrik ile şarj edilebiliyorsa, emisyonlar EV'lerin tüm yaşam döngüleri için önemli ölçüde azaltılabilir (Dias et al., 2014; Hennings, Mischinger, \& Linssen, 2013; McLaren, Miller, O'Shaughnessy, Wood, \& Shapiro, 2016). Brezilya'da yapılan bir araştırmaya göre Brezilya filosunda EV sayısındaki artışın neden olduğu elektrik enerjisi talebi çevre dostu ve olumlu şekilde karşılanabilmektedir (De Souza et al., 2018). Brezilya, ICE'lerde yakıt olarak şeker kamışı etanol kullanımı nedeniyle yenilenebilir ve sürdürülebilir bir enerji matrisine sahiptir (Silva Lora et al., 2011). Elektrik üretiminde düşük karbon salınımı sağlayabilen bir ülkede EV'ler için yapılan yaşam döngüsü analizi $\mathrm{CO}_{2}$ emisyonlarında düşüş sağlanabildiğini belirlemiştir (Doucette \& McCulloch, 2011; Ensslen et al., 2017). 
Tablo 5. ICEV Motorlu Araçlar ile Elektrikli Araçların Karşılaştırılması

\begin{tabular}{|l|l|l|}
\hline Kriterler & İçten Yanmalı Motorlu Araçlar (ICEV) & Elektrikli Araçlar (EV) \\
\hline Güç aktarma organı & ICEV motoru & Elektrik motoru \\
\hline Enerji seviyesi & Yüksek özgül yakıt enerjisi & Düşük pil seviyesi \\
\hline Güç yoğunluğu & Yüksek & Düşük \\
\hline Sera gazı emisyonu & Var & Yok (BEV), Düşük (HEV) \\
\hline Egzoz emisyonu & Var & Yok (BEV), Düşük (HEV) \\
\hline Menzil & $>300$ mil / tam dolu depo & $<100$ mil / tam şarjlı batarya \\
\hline Dolum/Şarj süresi & Kısa (<5 dakika) & Uzun (0,5 - 8 saat) \\
\hline $\begin{array}{l}\text { Yakıt } \\
\text { deposu/Batarya }\end{array}$ & Daha az yer kaplar & Çok fazla yer kaplar \\
\hline $\begin{array}{l}\text { Yakıt/Batarya } \\
\text { ağırlığ1 }\end{array}$ & Çok az & Çok yüksek \\
\hline Bakım maliyetleri & Daha yüksek & Daha düşük \\
\hline Fren enerjisi & Geri kazanmaz & Geri kazanabilir (HEV) \\
\hline İşletme maliyeti & Yüksek & Düşük \\
\hline Motor verimi & $\sim \%$ 30 & \% 80 \\
\hline Vites & Karmaşık dişli sistemine ihtiyaç var & Sadece bir vitese ihtiyaç var \\
\hline Gürültü & Yüksek & Sessiz \\
\hline Altyap1 & Gelişmiş & Şarj altyapı eksikliği \\
\hline $\begin{array}{l}\text { Tork } \\
\text { Maksimum tork sağlamak için biraz hız } \\
\text { toplamanız gerekir }\end{array}$ & $\begin{array}{l}\text { Motor çalıştıktan hemen sonra } \\
\text { anında maksimum tork üretir }\end{array}$ \\
\hline Enerji kaynağ1 & Sadece hidrokarbon kullanır & $\begin{array}{l}\text { Birçok kaynaktan üretilen elektriği } \\
\text { kullanabilir }\end{array}$ \\
\hline
\end{tabular}

\subsubsection{Hibrit Araçlar (HEV)}

Bir HEV, sürüş gücü sağlamak için iki farklı güç kaynağını birleştiren hibrit araç türüdür. Tipik olarak, HEV'ler standart bir içten yanmalı motor (ICE) ve bir elektrik motoruna bağlı bir pil takımı ile donatılmıştır (Hannan, Azidin, \& Mohamed, 2014). Akünün ve elektrik motoru sisteminin mevcudiyeti ya geleneksel bir ICE aracından daha iyi araç yakıt ekonomisi veya daha iyi performans elde etmeyi amaçlar. Bu temelde, düşük verimli ICE'nin batarya gibi daha yüksek verimli bir güç kaynağıyla birlikte kullanılması nedeniyle elde edilir. Şu anda, otomotiv pazarında çeşitli HEV tipleri bulunmaktadır. Elektrik motorunun maksimum gücü ile güç aktarma sisteminin maksimum gücü arasındaki oran hibridizasyon oranı olarak adlandırılır. Hibridizasyon oranı ne kadar yüksek ise elektrik motorunun kullanım oranı o kadar yüksektir (Hamut, Dincer, \& Naterer, 2014). Hibridizasyon oranı düşük ise akaryakıt fazla miktarda kullanılmaktadır. (Poullikkas, 2015; Vidyanandan, 2018).

\subsubsection{Seri HEV}

Seri HEV'ler basit bir güç akış mekanizmasına sahiptir (Chan, Bouscayrol, \& Chen, 2010). Aracı sürmek için gereken toplam tork, yalnızca çekiş motoru tarafından sağlanır. Bununla birlikte, ICE aküyü şarj etmek için kullanılır ve genellikle düşük yakıt tüketimi ile en uygun verimlilik noktasında çalıştırılır. ICE, akünün şarj durumuna göre açılır / kapanır ve akünün şarjını \%65-75 arasında tutar (A Emadi, Williamson, \& Khaligh, 2006). Seri HEV'ler saf elektrik ve saf motor modu, hibrit mod, rejeneratif fren modu, motor çekiş ve akü şarj modu ve hibrit akü şarj modu gibi farklı modlarda çalıştırılabilir. Enerji, iki kez motor jeneratöründen güç dönüştürücüsüne ve ayrıca çekiş motoruna dönüştürüldüğünde, bu yapılandırmada önemli miktarda enerji kaybı olur (Mehrdad Ehsani, Gao, \& Miller, 2007; Welchko \& Nagashima, 2003; Yong, Ramachandaramurthy, Tan, \& Mithulananthan, 2015). Jeneratör kullanımı, sistemin maliyetinin yanı sıra ağırlığı da arttırmaktadır (M. Ehsani, Gao, Gay, \& Emadi, 2005). Seri HEV'ler, askeri taşıtlar, otobüsler ve lokomotifler gibi ağır ticari taşıtlarda kullanılır (Mehrdad Ehsani et al., 2007) çünkü hacimli motor / jeneratör sistemi büyük taşıtlarda kolayca yerleştirilebilir. Debriyaj ve redüksiyon dişlisinin olmaması, güç aktarma sistemi tasarımında basitleştirme sağlar. Bu yapısıyla kısa yolculuklar ve şehir içi sürüş için uygundur (Chan, 2004; A Emadi et al., 2006; M. Sabri, Danapalasingam, \& Rahmat, 2016). Daha küçük ICE boyutu sadece jeneratörü çalıştırır ancak daha büyük akü paketi ve çekiş motoru ebadı bu konfigürasyonu paralel HEV'den daha pahalı hale getirir (M. Ehsani et al., 2005).

\subsubsection{Paralel HEV}

$\mathrm{Bu}$ yapılandırmada, hem motor hem de çekiş motoru, güç aktarımını tekerleklere yönlendirmek için paralel olarak 117 | P a g e www.iiste.org 
bağlanır. Düşük hızda EV motorunun çalışması tercih edilirken yüksek hızlarda ise sadece ICE çalışır (Rind et al., 2017). Paralel sistem, daha iyi performans elde etmek için daha küçük boyuttaki ICE ve elektrik motorunu kullanır ve genel sistem uyumu ve etkinliğini sağlar (Chan et al., 2010; Mehrdad Ehsani et al., 2007). Hem elektrik motoru hem de ICE üzerinden farklı çalışma modları etkinleştirilebilir. Daha az enerji dönüşümü vardır ve bu nedenle seri konfigürasyonlara kıyasla daha düşük enerji kaybı vardır (Delprat, Lauber, Guerra, \& Rimaux, 2004; C. C. Lin, Peng, Grizzle, \& Kang, 2001). Bu konfigürasyon kompakt özelliklerinden dolayı Honda Insight, Honda Civic ve Ford Escape gibi küçük araçlarda kullanılmıştır (Mehrdad Ehsani et al., 2007; Ali Emadi, Lee, \& Rajashekara, 2008).

\subsubsection{Seri-Paralel HEV}

$\mathrm{Bu}$ konfigürasyon, hem seri hem de paralel hibrit sistemin özelliklerine sahiptir. Bu konfigürasyonun iki farklı sınıflandırması daha vardır: elektrik ağırlıklı ve motor ağırlıklı (A Emadi et al., 2006). Daha verimli devirlere sahip olmak için daha küçük boyutlu ve yüksek verimli bir motor kullanılabilir. Ayrıca, ek elektrik jeneratörü ve planet dişlilerin kullanılması nedeniyle pahalıdır. Buna rağmen birçok otomobil üreticisi bu konfigürasyonu, araçları için daha iyi dinamik performans ve yüksek seyir hızı elde etmek için kullanmaktadırlar (Chen et al., 2009; Mehrdad Ehsani et al., 2007). Bu tasarım, hızlı ve yavaş sürüşte iki farklı güç kaynağını (elektrik motoru ve ICE motoru) kullanma esnekliğine sahip olup daha iyi yakıt ekonomisi ve daha düşük emisyon salınımı sağlayabilir (Rind et al., 2017).

\subsubsection{Fişli (Plug-in) HEV}

Fişli HEV'ler, $4 \mathrm{~kW}$-saat veya daha fazla bir pil depolama sistemine, pili harici bir kaynaktan şarj etmenin ve elektrik modunda en az 16 km sürüş yapabilme özelliğine sahip HEV'ler olarak tanımlanmaktadır (Pollet, Staffell, \& Shang, 2012). Verimlilik açısından, HEV tipleri arasında en verimli olanı Fişli HEV'lerdir. Fişli HEV'ler, bataryayı, ana şarj modunun olduğu HEV'lerde olduğu gibi uzatmak için ICE'yi kullanmaz. Bunun yerine, bu tür araçlarda, aracı standart bir elektrik prizine takarak elektrik şebekesi tarafindan tam olarak şarj edilebilen bir pil takımı bulunur. Ek olarak, rejeneratif frenleme ile şarj alternatifi Fişli HEV’lerin bir özelliğidir. Özellikle sera gazı emisyonları konusunda, Fişli HEV'lerin en büyük avantajlarından biri, aracı beslemek için kullanılan elektriğin, hidroelektrik, güneş veya rüzgâr gibi sıfır emisyonlu yenilenebilir enerji kaynakları dâhil olmak üzere herhangi bir enerji kaynağı kombinasyonundan temin edilmesidir. Böyle bir durumda, Fişli HEV'lerin sera gazı emisyonları diğer HEV'lere kıyasla çok daha düşük olacaktır (Galus, Zima, \& Andersson, 2010; Hennings et al., 2013). 2017 yılında yapılan bir çalışmaya göre Fişli HEV yeşil güç üretim profillerine göre sera gazı emisyonlarını azaltma potansiyeline sahiptir. Bu nedenle, Fişli HEV'lerin çevresel faydalarından tam olarak yararlanabilmeleri için, piyasaya çıkmaları, sıfır emisyonlu elektrik üretim teknolojileri ile birlikte kullanılması gerekmektedir (Requia, Adams, Arain, Koutrakis, \& Ferguson, 2017). Çeşitli çalışmalar, elektrik şebekesinden şarj edildiğinde, Fişli HEV'lerin tüm yakıt çevrimi boyunca geleneksel ICE araçlarına ve HEV'lerine göre daha az $\mathrm{CO}_{2}$ ve diğer kirleticileri yayabileceklerini ortaya koymuştur (Davies \& Kurani, 2013). Bu nedenle, Fişli HEV'ler şebekenin elektriğinin temiz kaynaktan elde edilmesi şartıyla, birçok bölgede ulaştırma sektörünün emisyon etkisini azaltabilir (Denholm, Kuss, \& Margolis, 2013).

\subsubsection{Bataryalı Elektrikli Araçlar (BEV)}

Bataryalı elektrikli araçlara, bataryada bulunan enerjiyi kullanan elektrik motoru güç verir (Poullikkas, 2015; Rind et al., 2017; Vidyanandan, 2018). Bu konfigürasyonlar BEV'ler ve yakıt hücreli elektrikli araçlar (FCEV) için benzerdir (Rind et al., 2017). BEV'lerde fosil yakıt tüketimi ve kullanım aşamasında herhangi bir egzoz emisyonu yoktur (Zhang \& Yao, 2015). Elektrikli araçlardaki en son yenilik, tekerlek içi yapılandırmadır (Rind et al., 2017; Vidyanandan, 2018). Bu tasarımda, her bir tekerleğe ayrı motorlar (tekerlek içi motorlar olarak bilinir) monte edilir. Motorun ve güç elektroniğinin tekerlek aksamına monte edilmesi verimliliği artırabilmekte, yerden tasarruf sağlayabilmekte ve tasarımcılara gövde tasarımında daha fazla esneklik sağlamaktadır. Herhangi bir karmaşık şanzımana veya tahrik miline ihtiyaç duyulmadan her bir tekerlekte tahrik torkunu ve frenleme kuvvetini bağımsız olarak düzenlemek mümkündür. Bu tekerleklerin rejeneratif frenleme kabiliyeti (yaklaşık \%85) çok yüksektir (Vidyanandan, 2018). Bu yapılandırma, sadece araç bileşenlerinin sayısını, şanzımandaki enerji kaybını, bakımı ve ağırlığı azaltmakla kalmaz, aynı zamanda genel sistem güvenilirliğini ve verimliliğini de arttırır (Fan, Zhang, Huang, \& Han, 2014). Bu tekerlek içi motor sistemi, yüksek tork ve düşük hızlı uygulamalar için kullanılır (Rahman et al., 2006). Bugün otomotiv pazarında çeşitli BEV'ler mevcuttur. En yeni üretilen BEV'ler en son teknolojiye sahip Li-ion pil takımlarını kullanır ve bu nedenle geliştirilmiş performansa sahiptir. Tipik bir BEV yaklaşık 120-390 km menzile ve en fazla $200 \mathrm{~km} /$ saat hıza sahiptir (Poullikkas, 2015).

İçten yanmalı motorlu araçlar (ICEV) ve BEV arasındaki benzerlik ICEV'lerin akaryakıt istasyonlarına bağımlı olmaları gibi BEV'lerin de bir elektrik kaynağına bağlanmak zorunda olmalarıdır (Vidyanandan, 2018). Bataryanın şarjı, Fişli HEV'lere benzer şekilde standart ev elektrik prizlerinde veya şarj istasyonlarında yapılabilir.

118 | P a g e

www.iiste.org 
HEV'ler ve Fişli HEV'lerde olduğu gibi, BEV'ler de geleneksel ICE araçlarına kıyasla ulaştırma sektörünün zararlı sera gazı emisyonlarında önemli bir azalma sağlama potansiyeline sahiptir. Bu durumda, BEV'lerin kullanılmasıyla sağlanan emisyon azaltma seviyesi Fişli HEV'lerden potansiyel olarak çok daha yüksektir (Tseng, $\mathrm{Wu}, \&$ Liu, 2013). Ulaştırma sektörünün sürdürebilirliği açısından alternatif teknolojiler arasında, BEV’ler genellikle ümit vaat eden bir seçenek olarak düşünülmektedir (Yuan, Li, Gou, \& Dong, 2015).

\subsubsection{Yakıt Hücreli Elektrikli Araçlar (FCEV)}

Yakıt hücreleri, temelde elektroliz sistemiyle çalışan cihazlardır. Bir yakıt hücresi, hidrojenin kimyasal enerjisini, elektrik enerjisine ve isıya dönüştüren elektrokimyasal bir cihazdır. Yakıt hücreli elektrikli araçlar (FCEV'ler) elektrikli taşımacılık endüstrisinde uzun vadeli bir gelecek potansiyeline sahiptir. Uygulanabilirliği ve işletme performansı, teknoloji geliştiricileri tarafindan araştırılmaktadır. FCEV'ler yıllarca süren araştırmalardan sonra EV ve HEV neslinin devamıdır. Bu teknolojiler aynı özellikleri paylaşsa da enerji kaynakları birbirinden farklıdır (Tanç, Arat, Baltacıŏ̆lu, \& Aydın, 2018).

Ulaştırma sektörünün sürdürebilirliği açısından en umut verici seçeneklerden biri de hidrojenin yakıt olarak kullanılmasıdır. Hidrojen ile çalışan araçlar (yakıt hücreli elektrikli araçlar, FCEV'ler) her ne kadar yüksek yakıt maliyeti ve hidrojen altyapısının olmaması bu araçların dezavantajı olarak görülse de hızla gelişen bir pazara sahiptir ve araştırmalara göre azımsanmayacak ölçüde potansiyel alıcısı bulunmaktadır. Bunun en önemli nedeni ise FCEV'lerin geleneksel taşıtların performansına benzer performans göstermeye başlamış olmasıdır. Buna iyi bir örnek, 2014 yılında Toyota tarafindan üretimi başlatılan ve yaklaşık $650 \mathrm{~km}$ menzile sahip, maksimum 175 $\mathrm{km} / \mathrm{saat}$ hıza çıkabilen ve 3 dakikadan daha kısa bir sürede tam tank yakıt ikmali yapan Toyota FCEV Mirai'dir (Brey, Carazo, \& Brey, 2018).

BEV'ler ve FCEV'lerin konfigürasyonları benzerdir. Avantajları arasında; geliştirilmiş araç gücü özelliği, tekerlek içi motor özelliği (Rind et al., 2017; Vidyanandan, 2018), daha iyi dinamik performans ile yüksek seyir hızı, daha iyi yakıt ekonomisi ve sıfır emisyon özellikleri bulunmaktadır. Dezavantajları ise; pahalı bir sistem olup karmaşık bir tasarıma sahip olmasidır (Rind et al., 2017).

\subsection{Elektrikli Araçlar ve Sürdürülebilir Ulaşım}

Ulaşım için yakıt kullanımını ve yerel hava kirliliğini azaltmak için EV'ler kesinlikle ICEV'lerden daha üstündür (Moriarty \& Wang, 2017). EV'lerin piyasaya yayılımının artması ulaşımdan kaynaklanan hava kirliliğinin önüne geçilmesi, sera gazı emisyonlarının ve enerji tüketiminin azalması için oldukça önemlidir (Moriarty \& Wang, 2017). Birçok araştırma elektrikli araçların kullanımının hızla arttığını ve gelecekte de otomotiv piyasasında önemli bir yer edineceğini söylemektedir. Mazur ve ark. (2015), düşük emisyonlu araçların hızlı bir şekilde tanıtılması ve yayılması ile sera gazı emisyonlarının azaltılabileceğini belirtmektedir (Mazur, Contestabile, Offer, \& Brandon, 2015). 2010'dan bu yana EV sayısı hızla artmıştır (IEA, 2019). Elektrikli araçlarla ulaşım, sürücüler tarafindan benimsenmiştir (Dijk, Orsato, \& Kemp, 2013). Kısa bir süre içerisinde, dünya otomobil üreticileri tarafindan bir milyon elektrikli araç üretilmiş, pazarlanmış ve satılmış olup bu yeni düşük karbonlu ileri teknolojilere de bir milyon sürücü alışmıştır (Martínez-Lao et al., 2017).

Dünya çapında birçok şehirde yapılan çalışmalar, elektrikli araçların geniş çaplı alımını desteklemek için tüketicilerin bilinçlendirilmesinin, iklim değişikliğini önleme stratejilerinin ve diğer politik önlemlerin gerekli ve faydalı olduğunu göstermiştir. Araştırmalara göre en çok iki neden EV taleplerinde artış sağlayacaktır: 1. Çevre bilinci olan tüketiciler, 2. EV sahiplerinin ucuz elektrik fiyatları ile araçlarını şarj etme imkânına sahip olması (Li et al., 2017). Bir dizi çalışmada ise EV alımını artırabilecek olan teşvik ve politika gereklilikleri araştırılmıştır (Bohnsack, Pinkse, \& Kolk, 2014; Gardner, Duell, \& Waller, 2013; Pasaoglu, Zubaryeva, Fiorello, \& Thiel, 2014; Tran, Banister, Bishop, \& McCulloch, 2013). Bir şehrin iklim değişikliğinin azaltılması stratejisinde EV'ye özgü bir politika varsa, o zaman bu şehirdeki EV'lerin sayısında (ya da kullanımında) bir artış olacağı sonucuna varılmıştır (Heidrich et al., 2017). Hükümetler, otomobil/batarya marka isimlerine bakmaksızın, şarj istasyonlarını standartlaştırmak için yeni yönetmelikler ve düzenlemeler oluşturmalıdır (Li et al., 2017). Literatürde bu hususta birçok araştırma mevcuttur. İngiltere'de İklim Değişikliği Yasası, ulaştırma sektöründeki emisyonların büyük bir kısmının içten yanmalı motorlu araçlardan kaynaklanması sebebiyle, karayolu taşımacıllı̆ı için ultra düşük karbonlu araçların alımını desteklemektedir (Heidrich et al., 2017). Vergi iadelerinin Kanada'daki hibrit araçların (HEV) satışı üzerindeki etkisi incelenmiş ve vergi indirimlerinin HEV'lerin pazar payını artırabileceği sonucu ortaya konulmuştur (Chandra, Gulati, \& Kandlikar, 2010). Benzer şekilde, Kore'de EV'lere verilen değer ile EV'lerin benimsenmesinde çevresel özelliklerin ve devlet desteğinin ılımlı etkisi belirlenmiştir (Kim, Oh, Park, \& Joo, 2018).

Elektrikli araçlar için ilave güç üretimi (yenilenebilir bir kaynaktan) ve altyapı gereksinimleri bir kısıtlama olarak vurgulanmıştır (Oxley et al., 2012). Hawkins ve arkadaşları, hem elektrik hem de ulaştırma sektörü tarafindan salınan net sera gazı emisyonlarında düşüş sağlamak için altyapının iyileştirilmesi ve yenilenebilir enerjinin payın artırılmasının EV'lerin yaygınlaştırılmasından önce yapılması gerektiğini belirlemiştir (Hawkins, Singh, Majeau-

119 | P a g e

www.iiste.org 
Bettez, \& Strømman, 2013). Benzer şekilde Tang ve ark. (2013), her otomobilin toplam enerji tüketimini ve $\mathrm{CO}_{2}$ emisyonlarını değerlendirdikleri çalışmada, Çin'deki EV'lerin uzun vadede çevre dostu olacağı ancak kısa vadede sınırlı bir etkiye sahip olacağı sonucuna varmışlardır (Tang, Wu, \& Zhang, 2013). Hofmann ve diğ. (2016), içten yanmalı motorlu araçların yerine elektrikli araçların kullanılmasında, elektrik üretim sektörünün enerji yapısını değiştirmemesi durumunda ulusal toplam $\mathrm{CO}_{2}$ emisyonlarının değişmeyeceğini kanıtlamaktadır (Hofmann, Guan, Chalvatzis, \& Huo, 2016). Ancak, Teixeira ve arkadaşlarının yapmış olduğu çalışmada ise, içten yanmalı motorlu araçların elektrikli araçlarla değiş̧irilmesinin $\mathrm{CO}_{2}$ emisyonları ve enerji tüketimi üzerindeki etkileri araştırılmış, elektrikli araçların içten yanmalı motorlu araç filosuna göre daha az $\mathrm{CO}_{2}$ emisyonu üreteceği belirtilmiştir (Teixeira \& Sodré, 2016). Mevcut çalışmalardaki farklı sonuçlara rağmen BEV'lerin daha temiz elektrik üretimi altında sera gazı emisyonlarını azaltma potansiyeline sahip olduğu yaygın olarak kabul edilmektedir (Hao, Cheng, Liu, \& Zhao, 2017). Bununla birlikte, sera gazı emisyonlarının azaltılması ekonomik açıdan da değerlendirilmelidir. BEV'ler, daha temiz bir elektrik şebekesi ile sera gazı emisyonlarını azaltabilecek olsa da, nispeten klasik araçlardan daha yüksek yatırım maliyetine sahiptir. Sera gazı emisyonunun azaltılmasında çok sayıda teknoloji olduğu için, BEV'in en ekonomik teknoloji olup olmadığ 1 konusunda şüpheleri olan araştırmacılar da bulunmaktadır (Rezvani, Jansson, \& Bodin, 2015; Ruan, Walker, \& Zhang, 2016). Literatürdeki çalışmalara göre toplam BEV maliyetinin geleneksel araçlardan daha yüksek olduğuna inanılmaktadır. Ancak uzun vadede elektrikli araçların içten yanmalı motorlu araçlara kıyasla çok daha ekonomik olacağı da kabul edilmektedir (Wu, Inderbitzin, \& Bening, 2015; Zhao, Doering, \& Tyner, 2015).

Mevcut konvansiyonel araçların elektrikli olan eşdeğeri ile değiştirilmesi ve filonun elektriklendirilmesinin $\mathrm{CO}_{2}$ emisyonlarında önemli oranda azalma sağlamaktadır. Bunun yanı sıra EV'lerin çevresel etkilerinin geniş perspektifte analizinin yapılabilmesi için "Yaşam Döngüsü Değerlendirmesi" (Life Cycle Assessment - LCA) çalışmaları da dikkate alınmalıdır. Bu konuda araştırmacılar tarafindan farklı sonuçlar elde edilmiştir (Heidrich et al., 2017). EV'nin tam yaşam döngüsü değerlendirmesi yapıldığında, EV kullanımının faydalarının daha önce hesaplananlardan daha yüksek olabileceği gösterilmiştir (Duarte, Gonçalves, \& Farias, 2016). Çek Cumhuriyeti ve Polonya'daki EV'lerin yaşam döngüsü değerlendirmesi 2015 (mevcut durum) ve 2050 yılları (yenilenebilir enerjinin daha çok kullanıldığı senaryo) için yapılmış olup çevresel etkileri kıyaslanmıştır. EV'lerin yenilenebilir enerji ile birlikte kullanılması durumunda çevresel etkilerinin azaldığı belirtilmiştir (Burchart-Korol et al., 2018). Benzer olarak Ma H. ve arkadaşları; Kaliforniya ve İngiltere şebekeleri için tam yaşam döngüsü esasına göre EV'lerin ve ICEV'lerin kullanımı ile atmosfere salınan sera gazı emisyonlarını karşılaştırmıştır. EV performansının düşük hızlı şehir içi sürüş koşullarında iyi sonuçlar verdiğini ve taşıt üretimindeki sera gazı emisyonlarının EV'lerde büyük ölçüde batarya üretimi nedeniyle ICEV üretiminden daha yüksek olduğunu bulmuşlardır (Ma, Balthasar, Tait, Riera-Palou, \& Harrison, 2012). Aynı şekilde Requia ve ark. (2017) Kanada'daki sekiz şehir için bir yaşam döngüsü analizi yaparak Fişli HEV'lerin $\mathrm{CO}_{2}$ emisyonlarını değerlendirmişlerdir. Çalışmada, yenilenebilir enerji ile üretilen elektriğin kullanımıyla $\mathrm{CO}_{2}$ emisyonunun çok büyük oranda azaltılabileceği belirtilmektedir (Requia et al., 2017). Çin'de yapılan birçok çalı̧̧ma EV'lerin kullanılmasının sera gazı emisyonlarında önemli oranda azalma sağlayacağı sonucuna varmıştır. Öyle ki bir araştırma, BEV bataryaları için ihtiyaç duyulan elektrik üretimi için kömür kullanılsa dahi sera gazı emisyonlarının azalacağını vurgulamaktadır (Ou, Yan, \& Zhang, 2010). BEV'lerin kullanımı ile sera gazı emisyonlarının azalacağını vurgulayan benzer çalışmalar da mevcuttur (Zhou, Ou, \& Zhang, 2013). Buna karşın, başka bir çalışma ise BEV'lerin sera gazı emisyonlarını arttıracağı sonucuna varmıştır (Wang et al., 2013). EV'ler için LCA yapıldığında diğer çevresel kazanımların küresel ısınma potansiyelinin ötesine geçtiğini bilmek gerekmektedir. Ulaşım sektöründe elektrikli araçların tercih edilmesiyle fosil yakıtlara daha az bağımlılık, karayolu ulaşımının sürdürülebilirliği gibi başka faydalar ortaya çıkmaktadır. Kentsel alanlardaki hava kirliliğine dair çevre bilincinin artması insan sağlı̆̆ üzerinde önemli sonuçlar doğurmaktadır. Sonuçta yenilenebilirliğin payı ile EV arasındaki bağlantı açıktır ve bu nedenle EV yaygınlaşmasını teşvik etmeden önce enerji üretim sektörünün sürdürülebilirliği önemlidir (Canals Casals, Martinez-Laserna, Amante García, \& Nieto, 2016).

\section{Sonuçlar}

Günümüzde fosil yakıtları yüksek oranda tüketen ulaştırma sektörü, küresel $\mathrm{CO}_{2}$ emisyonunun önemli bir bölümünden sorumludur. İklim değişikliğine ve yerel hava kirliliğine sebep olan emisyonların en aza indirilmesi gerekmektedir. Konvansiyonel yakıtlı araçların yerine sürdürülebilir ulaşım teknolojilerin kullanılması ile çevresel etkilerin (sera gazı emisyonları, fosil yakıtların tükenmesi, asidifikasyon, ötrofikasyon, insan toksisitesi ve partikül madde oluşumu vb.) önlenmesi bakımından büyük önem taşımaktadır. Araştırmacıların çoğu ulaştırma sektöründe sürdürülebilirliğin sağlanması için elektrikli araçlar ve alternatif yakıtların önemini vurgulamaktadır. Ulaştırma sektörünün geleceğine dair yapılan çalışmalar ve araştırmalar incelendiğinde; bu alandaki gelişmelerin, araştırmaların ve büyük yatırımların alternatif yakıtlar, elektrikli araçlar ve otonom sistemler gibi çevre dostu, yenilikçi ve daha güvenli sistemler üzerine kurulduğu görülmektedir. Alternatif yakıtlardan biyoyakıtlar (biyoetanol, biyodizel vb.) yıllardır birçok ülkede kullanılmış ve benimsenmiş olup halen kullanılmaya devam 
etmektedir. Ancak biyoyakıtlar, daha çok bölgesel tarım faaliyetlerine dayalı olduğundan küresel çapta uygulanabilirliği mümkün olamamaktadır. Elektrikli araçlar ise ulaşım sektörünün sürdürülebilir hale getirilmesinde gün geçtikçe daha fazla önem kazanmaktadır. Özellikle, elektrikli araçların şarj edilmesi için ihtiyaç duyulan enerjinin, yenilenebilir kaynaklardan elde edilmesi durumunda ulaştırma sektörünün sürdürülebilirliği sağlanacak ve çevresel etkiler en aza indirilmiş olacaktır. Elektrikli araçların kullanımının yaygınlaşması için tüketiciler bilinçlendirilmeli ve devlet teşviği sağlanmalıdır. Ayrıca, iklim değişikliği ile mücadele politikalarında elektrikli araçların kullanımının yaygınlaştırılması ile ilgili kesin hedefler yer almalı ve bu hedefler hem merkezi hem de yerel yönetimler tarafindan kararlılıkla uygulanmalıdır.

Türkiye'nin enerjide dışa bağımlı olduğu, bilinen bir gerçektir. Ayrıca, ülkemizin sera gazı emisyon miktarı da sürekli olarak artmaktadır. Şehirlerimizdeki hava kirleticilerinin konsantrasyonları da henüz Avrupa Birliği veya Dünya Sağlık Örgütü tarafından belirtilen sınır değerlerin altına inmemiştir. Enerjide dışa bağımlılığın azaltılması, karbondioksit ve diğer hava kirletici emisyonlarının en aza indirilebilmesi için elektrikli araçlar gibi yenilikçi ve sürdürülebilir çözümlerin bir an önce devreye sokulması gerekmektedir. Türkiye'nin İklim Değişikliği 6. Ulusal Bildirimi'nde ulaştırma sektöründe alternatif yakıtlı araçlar ve elektrikli araçlar ile ilgili yasal düzenlemeler yapılacağı ve bunların sayısının arttırılacağı belirtilmiş ancak kesin hedefler maalesef ortaya konulmamıştır. Bu konuda daha gerçekçi ve kesin hedefler belirlenmeli ve uygulanmalıdır.

\section{Kaynaklar}

Agency for Toxic Substances and Disease Registry (ATSDR). (1996). Toxicological profile for Methyl tertbutyl ether (MTBE). U.S. Department of Health and Human Services, (August), 268.

Amjad, S., Neelakrishnan, S., \& Rudramoorthy, R. (2010). Review of design considerations and technological challenges for successful development and deployment of plug-in hybrid electric vehicles. Renewable and Sustainable Energy Reviews, 14(3), 1104-1110. https://doi.org/10.1016/j.rser.2009.11.001

An, H., Yang, W. M., Maghbouli, A., Li, J., Chou, S. K., \& Chua, K. J. (2013). Performance, combustion and emission characteristics of biodiesel derived from waste cooking oils. Applied Energy, 112, 493-499. https://doi.org/10.1016/j.apenergy.2012.12.044

Araújo, K., Mahajan, D., Kerr, R., \& Silva, M. da. (2017). Global Biofuels at the Crossroads: An Overview of Technical, Policy, and Investment Complexities in the Sustainability of Biofuel Development. Agriculture, 7(4), 32. https://doi.org/10.3390/agriculture7040032

Atkinson, R. (2000). Atmospheric chemistry of VOCs and NOx. Atmospheric Environment, 34, $2063-2101$. https://doi.org/10.1016/S1352-2310(99)00460-4

Ban-Weiss, G. A., Chen, J. Y., Buchholz, B. A., \& Dibble, R. W. (2007). A numerical investigation into the anomalous slight NOx increase when burning biodiesel; A new (old) theory. Fuel Processing Technology, 88(7), 659-667. https://doi.org/10.1016/j.fuproc.2007.01.007

Bauer, C., Hofer, J., Althaus, H. J., Del Duce, A., \& Simons, A. (2015). The environmental performance of current and future passenger vehicles: Life Cycle Assessment based on a novel scenario analysis framework. Applied Energy, 157, 871-883. https://doi.org/10.1016/j.apenergy.2015.01.019

Bohnsack, R., Pinkse, J., \& Kolk, A. (2014). Business models for sustainable technologies: Exploring business model evolution in the case of electric vehicles. Research Policy, 43(2), 284-300. https://doi.org/10.1016/j.respol.2013.10.014

BP. (2018). BP Statistical Review of World Energy. Statistical Review of World Energy.

Brey, J. J., Carazo, A. F., \& Brey, R. (2018). Exploring the marketability of fuel cell electric vehicles in terms of infrastructure and hydrogen costs in Spain. Renewable and Sustainable Energy Reviews, 82, 2893-2899. https://doi.org/10.1016/j.rser.2017.10.042

Burchart-Korol, D., Jursova, S., Folęga, P., Korol, J., Pustejovska, P., \& Blaut, A. (2018). Environmental life cycle assessment of electric vehicles in Poland and the Czech Republic. Journal of Cleaner Production, 202(October 2014), 476-487. https://doi.org/10.1016/j.jclepro.2018.08.145 
Canals Casals, L., Martinez-Laserna, E., Amante García, B., \& Nieto, N. (2016). Sustainability analysis of the electric vehicle use in Europe for CO2 emissions reduction. Journal of Cleaner Production, 127, 425-437. https://doi.org/10.1016/j.jclepro.2016.03.120

Cecere, G., Corrocher, N., \& Guerzoni, M. (2018). Price or performance? A probabilistic choice analysis of the intention to buy electric vehicles in European countries. Energy Policy, 118(March), 19-32. https://doi.org/10.1016/j.enpol.2018.03.034

Chan, C. C. (2004). The State of the Art of Electric Vehicles. Journal of Asian Electric Vehicles, 2(2), 579600. https://doi.org/10.1109/JPROC.2007.892489

Chan, C. C., Bouscayrol, A., \& Chen, K. (2010). Electric , Hybrid , and Fuel-Cell Vehicles : Architectures and Modeling, 59(2), 589-598. https://doi.org/10.1109/TVT.2009.2033605

Chandra, A., Gulati, S., \& Kandlikar, M. (2010). Green drivers or free riders? An analysis of tax rebates for hybrid vehicles. Journal of Environmental Economics and Management, 60(2), 78-93. https://doi.org/10.1016/j.jeem.2010.04.003

Chattopadhyay, S., \& Sen, R. (2013). Fuel properties, Engine performance and environmental benefits of biodiesel produced by a green process. Applied Energy, 105, 319-326. https://doi.org/10.1016/j.apenergy.2013.01.003

Chellaswamy, C., \& Ramesh, R. (2017). Future renewable energy option for recharging full electric vehicles. Renewable and Sustainable Energy Reviews, 76(March), 824-838. https://doi.org/10.1016/j.rser.2017.03.032

Chen, K., Bouscayrol, A., Berthon, A., Delarue, P., Hissel, D., \& Trigui, R. (2009). Global Modeling of Different Vehicles. IEEE Vehicular Technology Magazine, 10, 80-89.

ÇŞB. (2018). Çevresel Göstergeler 2016. Ankara: T.C. ÇEVRE VE ŞEHİRCİLIKK BAKANLIĞI.

Davies, J., \& Kurani, K. S. (2013). Moving from assumption to observation: Implications for energy and emissions impacts of plug-in hybrid electric vehicles. Energy Policy, 62, 550-560. https://doi.org/10.1016/j.enpol.2013.06.126

De Souza, L. L. P., Lora, E. E. S., Palacio, J. C. E., Rocha, M. H., Renó, M. L. G., \& Venturini, O. J. (2018). Comparative environmental life cycle assessment of conventional vehicles with different fuel options, plugin hybrid and electric vehicles for a sustainable transportation system in Brazil. Journal of Cleaner Production, 203, 444-468. https://doi.org/10.1016/j.jclepro.2018.08.236

Delprat, S., Lauber, J., Guerra, T. M., \& Rimaux, J. (2004). Control of a parallel hybrid powertrain: Optimal control. IEEE Transactions on Vehicular Technology, 53(3), 872-881. https://doi.org/10.1109/TVT.2004.827161

Denholm, P., Kuss, M., \& Margolis, R. M. (2013). Co-benefits of large scale plug-in hybrid electric vehicle and solar PV deployment. Journal of Power Sources, 236, 350-356. https://doi.org/10.1016/j.jpowsour.2012.10.007

Dias, M. V. X., Haddad, J., Horta Nogueira, L., Costa Bortoni, E. da, Passos da Cruz, R. A., Akira Yamachita, R., \& Goncalves, J. L. (2014). The impact on electricity demand and emissions due to the introduction of electric cars in the São Paulo power system. Energy Policy, 65, $298-304$. https://doi.org/10.1016/j.enpol.2013.09.052

Dijk, M., Orsato, R. J., \& Kemp, R. (2013). The emergence of an electric mobility trajectory. Energy Policy, 52, 135-145. https://doi.org/10.1016/j.enpol.2012.04.024 
Doucette, R. T., \& McCulloch, M. D. (2011). Modeling the CO2 emissions from battery electric vehicles given the power generation mixes of different countries. Energy Policy, 39(2), 803-811. https://doi.org/10.1016/j.enpol.2010.10.054

Duarte, G. O., Gonçalves, G. A., \& Farias, T. L. (2016). Analysis of fuel consumption and pollutant emissions of regulated and alternative driving cycles based on real-world measurements. Transportation Research Part D: Transport and Environment, 44, 43-54. https://doi.org/10.1016/j.trd.2016.02.009

Dutta, K., Daverey, A., \& Lin, J. G. (2014). Evolution retrospective for alternative fuels: First to fourth generation. Renewable Energy, 69, 114-122. https://doi.org/10.1016/j.renene.2014.02.044

EEA. (2018). Emissions of air pollutants from transport. Retrieved from https://www.eea.europa.eu/data-andmaps/indicators/transport-emissions-of-air-pollutants-8/transport-emissions-of-air-pollutants-6

Ehsani, M., Gao, Y., Gay, S. E., \& Emadi, A. (2005). Modern Electric, Hybrid Electric, and Fuel Cell Vehicles.

Ehsani, M., Gao, Y., \& Miller, J. M. (2007). Hybrid electric vehicles: Architecture and motor drives. Proceedings of the IEEE, 95(4), 719-728. https://doi.org/10.1109/JPROC.2007.892492

Emadi, A., Lee, Y. J., \& Rajashekara, K. (2008). Power electronics and motor drives in electric, hybrid electric, and plug-in hybrid electric vehicles. IEEE Transactions on Industrial Electronics, 55(6), 2237-2245. https://doi.org/10.1109/TIE.2008.922768

Emadi, A., Williamson, S. S., \& Khaligh, A. (2006). Power Electronics Intensive Solutions for Advanced Vehicular Power Systems. IEEE Transactions on Power Electronics, 21(3), 567-577. https://doi.org/10.1109/TPEL.2006.872378

Ensslen, A., Schücking, M., Jochem, P., Steffens, H., Fichtner, W., Wollersheim, O., \& Stella, K. (2017). Empirical carbon dioxide emissions of electric vehicles in a French-German commuter fleet test. Journal of Cleaner Production, 142, 263-278. https://doi.org/10.1016/j.jclepro.2016.06.087

Fan, Y., Zhang, L., Huang, J., \& Han, X. (2014). Design, analysis, and sensorless control of a self-decelerating permanent-magnet in-wheel motor. IEEE Transactions on Industrial Electronics, 61(10), 5788-5797. https://doi.org/10.1109/TIE.2014.2300065

Figenbaum, E. (2017). Perspectives on Norway's supercharged electric vehicle policy. Environmental Innovation and Societal Transitions, 25, 14-34. https://doi.org/10.1016/j.eist.2016.11.002

Flachsbart, P. G. (1997). Human Exposure to Exhaust And Evaporative Emissions from Motor Vehicles. In D. Schwela, O. Zali, \& P. Schwela (Eds.), Motor Vehicle Air Pollution (pp. 132-180). World Health Organization.

Galus, M. D., Zima, M., \& Andersson, G. (2010). On integration of plug-in hybrid electric vehicles into existing power system structures. Energy Policy, 38(11), 6736-6745. https://doi.org/10.1016/j.enpol.2010.06.043

Ganapathy, T., Gakkhar, R. P., \& Murugesan, K. (2011). Influence of injection timing on performance, combustion and emission characteristics of Jatropha biodiesel engine. Applied Energy, 88(12), 4376-4386. https://doi.org/10.1016/j.apenergy.2011.05.016

Gardner, L. M., Duell, M., \& Waller, S. T. (2013). A framework for evaluating the role of electric vehicles in transportation network infrastructure under travel demand variability. Transportation Research Part A: Policy and Practice, 49, 76-90. https://doi.org/10.1016/j.tra.2013.01.031

Graboski, M. S., \& Mccormick, R. L. (1998). Combustion of Fat and Vegetable Oil Derived Fuels in Diesel Engines. Progress in Energy and Combustion Science, 24(97), 125-164. 
Hamut, H. S., Dincer, I., \& Naterer, G. F. (2014). Analysis and optimization of hybrid electric vehicle thermal management systems. Journal of Power Sources, 247, 643-654. https://doi.org/10.1016/j.jpowsour.2013.08.131

Hannan, M. A., Azidin, F. A., \& Mohamed, A. (2014). Hybrid electric vehicles and their challenges: A review. Renewable and Sustainable Energy Reviews, 29, 135-150. https://doi.org/10.1016/j.rser.2013.08.097

Hao, H., Cheng, X., Liu, Z., \& Zhao, F. (2017). Electric vehicles for greenhouse gas reduction in China: A costeffectiveness analysis. Transportation Research Part D, 56, 68-84. https://doi.org/10.1016/j.trd.2017.07.025

Hawkins, T. R., Singh, B., Majeau-Bettez, G., \& Strømman, A. H. (2013). Comparative Environmental Life Cycle Assessment of Conventional and Electric Vehicles. Journal of Industrial Ecology, 17(1), 53-64. https://doi.org/10.1111/j.1530-9290.2012.00532.x

He, B. Q., Wang, J. X., Hao, J. M., Yan, X. G., \& Xiao, J. H. (2003). A study on emission characteristics of an EFI engine with ethanol blended gasoline fuels. Atmospheric Environment, 37(7), 949-957. https://doi.org/10.1016/S1352-2310(02)00973-1

Heidrich, O., Hill, G. A., Neaimeh, M., Huebner, Y., Blythe, P. T., \& Dawson, R. J. (2017). How do cities support electric vehicles and what difference does it make? Technological Forecasting and Social Change, 123(November 2016), 17-23. https://doi.org/10.1016/j.techfore.2017.05.026

Heinrichs, H. U., \& Jochem, P. (2016). Long-term impacts of battery electric vehicles on the German electricity system. European Physical Journal: Special Topics, 225(3), 583-593. https://doi.org/10.1140/epjst/e201550115-X

Hennings, W., Mischinger, S., \& Linssen, J. (2013). Utilization of excess wind power in electric vehicles. Energy Policy, 62(2013), 139-144. https://doi.org/10.1016/j.enpol.2013.06.134

Hofmann, J., Guan, D., Chalvatzis, K., \& Huo, H. (2016). Assessment of electrical vehicles as a successful driver for reducing CO2emissions in China. Applied Energy, 184, 995-1003. https://doi.org/10.1016/j.apenergy.2016.06.042

Hsieh, W.-D., Chen, R.-H., Wu, T.-L., \& Lin, T.-H. (2002). Engine performance and pollutant emission of an SI engine using ethanol-gasoline blended fuels. Atmospheric Environment, 36, 403-410. https://doi.org/10.1016/S1352-2310(01)00508-8

IEA. (2018). CO2 Emissions Statistics. Retrieved from https://www.iea.org/statistics/co2emissions/

IEA. (2019). Transport. Retrieved from https://www.iea.org/topics/transport/

Igliński, H., \& Babiak, M. (2017). Analysis of the Potential of Autonomous Vehicles in Reducing the Emissions of Greenhouse Gases in Road Transport. Procedia Engineering, 192(June), 353-358. https://doi.org/10.1016/j.proeng.2017.06.061

Joshi, G., Pandey, J. K., Rana, S., \& Rawat, D. S. (2017). Challenges and opportunities for the application of biofuel. Renewable and Sustainable Energy Reviews, 79(May), 850-866. https://doi.org/10.1016/j.rser.2017.05.185

Kim, M. K., Oh, J., Park, J. H., \& Joo, C. (2018). Perceived value and adoption intention for electric vehicles in Korea: Moderating effects of environmental traits and government supports. Energy, 159, 799-809. https://doi.org/10.1016/j.energy.2018.06.064

Knapp, K. T., Stump, F. D., \& Tejada, S. B. (1998). The Effect of Ethanol Fuel on the Emissions of Vehicles over a Wide Range of Temperatures. Journal of the Air and Waste Management Association, 48(7), 646653. https://doi.org/10.1080/10473289.1998.10463710 
Knothe, G., \& Steidley, K. R. (2005). Kinematic viscosity of biodiesel fuel components and related compounds. Influence of compound structure and comparison to petrodiesel fuel components. Fuel, 84(9), 1059-1065. https://doi.org/10.1016/j.fuel.2005.01.016

Kousoulidou, M., Fontaras, G., Mellios, G., \& Ntziachristos, L. (2008). Effect of biodiesel and bioethanol on exhaust emissions. European Topic Centre on Air Pollution and Climate Change, 5(February), 1-52.

Lahane, S., \& Subramanian, K. A. (2015). Effect of different percentages of biodiesel-diesel blends on injection, spray, combustion, performance, and emission characteristics of a diesel engine. Fuel, 139, $537-$ 545. https://doi.org/10.1016/j.fuel.2014.09.036

Lapuerta, M., Armas, O., Ballesteros, R., \& Fernández, J. (2005). Diesel emissions from biofuels derived from Spanish potential vegetable oils. Fuel, 84(6 SPEC. ISS.), 773-780. https://doi.org/10.1016/j.fuel.2004.11.010

Li, X., Chen, P., \& Wang, X. (2017). Impacts of renewables and socioeconomic factors on electric vehicle demands - Panel data studies across 14 countries. Energy Policy, 109(May), 473-478. https://doi.org/10.1016/j.enpol.2017.07.021

Liew, W. H., Hassim, M. H., \& Ng, D. K. S. (2014). Review of evolution, technology and sustainability assessments of biofuel production. Journal of Cleaner Production, 71, 11-29. https://doi.org/10.1016/j.jclepro.2014.01.006

Lin, B., \& Xie, C. (2013). Estimation on oil demand and oil saving potential of China's road transport sector. Energy Policy, 61, 472-482. https://doi.org/10.1016/j.enpol.2013.06.017

Lin, C. C., Peng, H., Grizzle, J. W., \& Kang, J. M. (2001). Power management strategy for a parallel hybrid electric truck. IEEE Trans Control Syst Technol. IEEE Transactions on Control Systems Technology, 11(6), 839-849. https://doi.org/10.1109/TCST.2003.815606

M. Sabri, M. F., Danapalasingam, K. A., \& Rahmat, M. F. (2016). A review on hybrid electric vehicles architecture and energy management strategies. Renewable and Sustainable Energy Reviews, 53, 14331442. https://doi.org/10.1016/j.rser.2015.09.036

Ma, H., Balthasar, F., Tait, N., Riera-Palou, X., \& Harrison, A. (2012). A new comparison between the life cycle greenhouse gas emissions of battery electric vehicles and internal combustion vehicles. Energy Policy, 44, 160-173. https://doi.org/10.1016/j.enpol.2012.01.034

Martínez-Lao, J., Montoya, F. G., Montoya, M. G., \& Manzano-Agugliaro, F. (2017). Electric vehicles in Spain: An overview of charging systems. Renewable and Sustainable Energy Reviews, 77(November 2016), 970-983. https://doi.org/10.1016/j.rser.2016.11.239

Mazur, C., Contestabile, M., Offer, G. J., \& Brandon, N. P. (2015). Assessing and comparing German and UK transition policies for electric mobility. Environmental Innovation and Societal Transitions, 14, 84-100. https://doi.org/10.1016/j.eist.2014.04.005

McGee, M. (2019). Earth's CO2 Home Page. Retrieved from https://www.co2.earth/

McLaren, J., Miller, J., O’Shaughnessy, E., Wood, E., \& Shapiro, E. (2016). CO2emissions associated with electric vehicle charging: The impact of electricity generation mix, charging infrastructure availability and vehicle type. Electricity Journal, 29(5), 72-88. https://doi.org/10.1016/j.tej.2016.06.005

Merkisz-Guranowska, A., Merkisz, J., Kozak, M., \& Jacyna, M. (2013). Development of a sustainable road transport system. WIT Transactions on the Built Environment, 130, 507-517. https://doi.org/10.2495/UT130411 
Meshram, D., Thote, S., Singh, N., \& Pakhare, K. (2013). ALGAE FUEL TECHNOLOGY-CONCEPT OF REVOLUTIONARY FUTURE. International Journal of Applied Engineering Research and Development (IJAERD), 3(3), 15-28.

Moriarty, P., \& Wang, S. J. (2017). Can Electric Vehicles Deliver Energy and Carbon Reductions? Energy Procedia, 105, 2983-2988. https://doi.org/10.1016/j.egypro.2017.03.713

Nanaki, E. A., \& Koroneos, C. J. (2013). Comparative economic and environmental analysis of conventional, hybrid and electric vehicles - The case study of Greece. Journal of Cleaner Production, 53, 261-266. https://doi.org/10.1016/j.jclepro.2013.04.010

Ng, J. H., Ng, H. K., \& Gan, S. (2012). Characterisation of engine-out responses from a light-duty diesel engine fuelled with palm methyl ester (PME). Applied Energy, 90(1), 58-67. https://doi.org/10.1016/j.apenergy.2011.01.028

OECD. (2018). Emissions of air pollutants. Retrieved from https://stats.oecd.org/

Offer, G. J., Howey, D., Contestabile, M., Clague, R., \& Brandon, N. P. (2010). Comparative analysis of battery electric, hydrogen fuel cell and hybrid vehicles in a future sustainable road transport system. Energy Policy, 38(1), 24-29. https://doi.org/10.1016/j.enpol.2009.08.040

Ou, X., Yan, X., \& Zhang, X. (2010). Using coal for transportation in China: Life cycle GHG of coal-based fuel and electric vehicle, and policy implications. International Journal of Greenhouse Gas Control, 4(5), 878-887. https://doi.org/10.1016/j.ijggc.2010.04.018

Oxley, T., Elshkaki, A., Kwiatkowski, L., Castillo, A., Scarbrough, T., \& ApSimon, H. (2012). Pollution abatement from road transport: Cross-sectoral implications, climate co-benefits and behavioural change. Environmental Science and Policy, 19-20, 16-32. https://doi.org/10.1016/j.envsci.2012.01.004

Pasaoglu, G., Zubaryeva, A., Fiorello, D., \& Thiel, C. (2014). Analysis of European mobility surveys and their potential to support studies on the impact of electric vehicles on energy and infrastructure needs in Europe. Technological Forecasting and Social Change, 87, 41-50. https://doi.org/10.1016/j.techfore.2013.09.002

Peura, P. (2013). From Malthus to sustainable energy - Theoretical orientations to reforming the energy sector. Renewable and Sustainable Energy Reviews, 19, 309-327. https://doi.org/10.1016/j.rser.2012.11.025

Pollet, B. G., Staffell, I., \& Shang, J. L. (2012). Current status of hybrid, battery and fuel cell electric vehicles: From electrochemistry to market prospects. Electrochimica Acta, 84, 235-249. https://doi.org/10.1016/j.electacta.2012.03.172

Poullikkas, A. (2015). Sustainable options for electric vehicle technologies. Renewable and Sustainable Energy Reviews, 41, 1277-1287. https://doi.org/10.1016/j.rser.2014.09.016

Raheman, H., \& Kumari, S. (2014). Performance and Emissions of Emulsified Biodiesel O perated Diesel Engine. International Conference on Biological, Civil and Environmental Engineering, 110-117. https://doi.org/10.15242/IICBE.C0314048

Rahman, K. M., Patel, N. R., Ward, T. G., Nagashima, J. M., Caricchi, F., \& Crescimbini, F. (2006). Application of Direct-Drive Wheel Motor for Fuel Cell Electric and Hybrid Electric Vehicle Propulsion System. IEEE Transactions on Industry Applications, 42(5), 1185-1192. https://doi.org/10.1109/TIA.2006.880886

Ramachandran, S., \& Stimming, U. (2015). Well to wheel analysis of low carbon alternatives for road traffic. Energy and Environmental Science, 8(11), 3313-3324. https://doi.org/10.1039/c5ee01512j

Requia, W. J., Adams, M. D., Arain, A., Koutrakis, P., \& Ferguson, M. (2017). Carbon dioxide emissions of plug-in hybrid electric vehicles: A life-cycle analysis in eight Canadian cities. Renewable and Sustainable Energy Reviews, 78(April 2017), 1390-1396. https://doi.org/10.1016/j.rser.2017.05.105 
Resch, J., Klinger, R., Taddei, U., \& Baker, E. (2018). Diesel-Fahrverbote für saubere Luft auch für Euro 5 Diesel in 2018 nicht mehr aufzuhalten - Schriftliche Urteilsbegründung des Bundesverwaltungsgerichts liegt vor und ist eindeutig. https://www.duh.de/presse/pressemitteilungen/pressemitteilung/diesel-fahrverbote-fuer-saubere-luft-auchfuer-euro-5-diesel-in-2018-nicht-mehr-aufzuhalten-schriftl/

Rezvani, Z., Jansson, J., \& Bodin, J. (2015). Advances in consumer electric vehicle adoption research: A review and research agenda. Transportation Research Part D: Transport and Environment, 34, $122-136$. https://doi.org/10.1016/j.trd.2014.10.010

Rind, S. J., Ren, Y., Hu, Y., Wang, J., \& Jiang, L. (2017). Configurations and control of traction motors for electric vehicles: A review. Chinese Journal of Electrical Engineering, 3(3), 1-17. https://doi.org/10.23919/CJEE.2017.8250419

Romieu, I. (1997). Epidemiological Studies of the Health Effects of Air Pollution due to Motor Vehicles. In P. Schwela, Dietrich; Zali, Olivier; Schwela (Ed.), Motor Vehicle Air Pollution Public Health Impact And Control Measures (pp. 27-106). Geneva.

Ruan, J., Walker, P., \& Zhang, N. (2016). A comparative study energy consumption and costs of battery electric vehicle transmissions. Applied Energy, 165, 119-134. https://doi.org/10.1016/j.apenergy.2015.12.081

Ruiz, V., Pfrang, A., Kriston, A., Omar, N., Van den Bossche, P., \& Boon-Brett, L. (2018). A review of international abuse testing standards and regulations for lithium ion batteries in electric and hybrid electric vehicles. Renewable and Sustainable Energy Reviews, 81(April 2017), 1427-1452. https://doi.org/10.1016/j.rser.2017.05.195

Shirneshan, A., Almassi, M., Ghobadian, B., Borghei, A. L. I. M., \& Najafi, G. H. (2012). Effects of Biodiesel and Engine Load on Some Emission Characteristics of a Direct Injection Diesel Engine. Current World Enviroment, 7(2), 207-212. https://doi.org/10.12944/CWE.7.2.03

Silva Lora, E. E., Escobar Palacio, J. C., Rocha, M. H., Grillo Renó, M. L., Venturini, O. J., \& Almazán del Olmo, O. (2011). Issues to consider, existing tools and constraints in biofuels sustainability assessments. Energy, 36(4), 2097-2110. https://doi.org/10.1016/j.energy.2010.06.012

Sozinho, D. W. F., Gallardo, A. L. C. F., Duarte, C. G., Ramos, H. R., \& Ruiz, M. S. (2018). Towards strengthening sustainability instruments in the Brazilian sugarcane ethanol sector. Journal of Cleaner Production, 182, 437-454. https://doi.org/10.1016/j.jclepro.2018.01.261

Tanç, B., Arat, H. T., Baltacığglu, E., \& Aydın, K. (2018). Overview of the next quarter century vision of hydrogen fuel cell electric vehicles. International Journal of Hydrogen Energy. https://doi.org/10.1016/j.ijhydene.2018.10.112

Tang, B. jun, Wu, X. feng, \& Zhang, X. (2013). Modeling the CO2emissions and energy saved from new energy vehicles based on the logistic-curve. Energy Policy, 57, 30-35. https://doi.org/10.1016/j.enpol.2012.06.021

Teixeira, A. C. R., \& Sodré, J. R. (2016). Simulation of the impacts on carbon dioxide emissions from replacement of a conventional Brazilian taxi fleet by electric vehicles. Energy, 115, 1617-1622. https://doi.org/10.1016/j.energy.2016.07.095

Tran, M., Banister, D., Bishop, J. D. K., \& McCulloch, M. D. (2013). Simulating early adoption of alternative fuel vehicles for sustainability. Technological Forecasting and Social Change, 80(5), 865-875. https://doi.org/10.1016/j.techfore.2012.09.009

Tseng, H. K., Wu, J. S., \& Liu, X. (2013). Affordability of electric vehicles for a sustainable transport system: An economic and environmental analysis. Energy Policy, 61, 441-447. https://doi.org/10.1016/j.enpol.2013.06.026 
TUIK. (2018). Ulaştırma İstatistikleri. Retrieved from http://www.tuik.gov.tr/PreTablo.do?alt_id=1051

Türkiye Petrolleri. (2016). Ham Petrol ve Doğal Gaz Sektör Raporu.

Van Lier, T., \& Macharis, C. (2014). Assessing the environmental impact of inland waterway transport using a life-cycle assessment approach: The case of Flanders. Research in Transportation Business and Management, 12, 29-40. https://doi.org/10.1016/j.rtbm.2014.08.003

Van Vliet, O., Brouwer, A. S., Kuramochi, T., Van Den Broek, M., \& Faaij, A. (2011). Energy use, cost and CO2 emissions of electric cars. Journal of Power Sources, 196(4), 2298-2310. https://doi.org/10.1016/j.jpowsour.2010.09.119

Vidyanandan, K. V. (2018). Overview of electric machines for electric and hybrid vehicles. Energy Scan, 3, $7-$ 14. https://doi.org/10.1504/IJVD.2014.057775

Wang, D., Zamel, N., Jiao, K., Zhou, Y., Yu, S., Du, Q., \& Yin, Y. (2013). Life cycle analysis of internal combustion engine, electric and fuel cell vehicles for China. Energy, 59(2013), 402-412. https://doi.org/10.1016/j.energy.2013.07.035

Welchko, B. A., \& Nagashima, J. M. (2003). The influence of topology selection on the design of EV/HEV propulsion systems. IEEE Power Electronics Letters, 1(2), 36-40. https://doi.org/10.1109/LPEL.2003.821033

Wu, G., Inderbitzin, A., \& Bening, C. (2015). Total cost of ownership of electric vehicles compared to conventional vehicles: A probabilistic analysis and projection across market segments. Energy Policy, 80, 196-214. https://doi.org/10.1016/j.enpol.2015.02.004

Xue, J., Grift, T. E., \& Hansen, A. C. (2011). Effect of biodiesel on engine performances and emissions. Renewable and Sustainable Energy Reviews, 15, 1098-1116. https://doi.org/10.1016/j.rser.2010.11.016

Yong, J. Y., Ramachandaramurthy, V. K., Tan, K. M., \& Mithulananthan, N. (2015). A review on the state-ofthe-art technologies of electric vehicle, its impacts and prospects. Renewable and Sustainable Energy Reviews, 49, 365-385. https://doi.org/10.1016/j.rser.2015.04.130

Yuan, X., Li, L., Gou, H., \& Dong, T. (2015). Energy and environmental impact of battery electric vehicle range in China. Applied Energy, 157, 75-84. https://doi.org/10.1016/j.apenergy.2015.08.001

Zhang, R., \& Yao, E. (2015). Electric vehicles' energy consumption estimation with real driving condition data. Transportation Research Part D: Transport and Environment, 41, 177-187. https://doi.org/10.1016/j.trd.2015.10.010

Zhao, X., Doering, O. C., \& Tyner, W. E. (2015). The economic competitiveness and emissions of battery electric vehicles in China. Applied Energy, 156, 666-675. https://doi.org/10.1016/j.apenergy.2015.07.063

Zhou, G., Ou, X., \& Zhang, X. (2013). Development of electric vehicles use in China: A study from the perspective of life-cycle energy consumption and greenhouse gas emissions. Energy Policy, 59(2013), 875884. https://doi.org/10.1016/j.enpol.2013.04.057

Zhu, H., Bohac, S. V., Nakashima, K., Hagen, L. M., Huang, Z., \& Assanis, D. N. (2013). Effect of fuel oxygen on the trade-offs between soot, NOxand combustion efficiency in premixed low-temperature diesel engine combustion. Fuel, 112(x), 459-465. https://doi.org/10.1016/j.fuel.2013.05.023 